\title{
The Rate Elasticity of Retail Deposits in the United Kingdom: A Macroeconomic Investigation*
}

\author{
Ching-Wai (Jeremy) Chiu and John Hill \\ Bank of England
}

This paper quantitatively studies the behavior of major banks' household deposit funding in the United Kingdom. We estimate a panel of Bayesian vector autoregression models on a unique data set compiled by the Bank of England, and identify deposit demand and supply shocks, both to individual banks and in aggregate, using microfounded sign restrictions. Based on the impulse responses, we estimate by how much banks would be required to increase their deposit rates to cover a deposit gap caused by funding shocks. Banks generally find it costly to bid up for deposits to cover a funding gap in the short run. The elasticity of household deposits with respect to the interest rate paid is typically of the order of 0.3 , indicating that retail deposits are rate inelastic. But this varies across banks and the types of shock conditioned on. We also show evidence that banks are more vulnerable to deposit supply shocks than to deposit demand shocks. Historical decompositions uncover plausible shock dynamics in the historical data.

JEL Codes: C11, E40, G21.

${ }^{*}$ The authors thank Professor Harrison Hong, the editor, and an anonymous referee for very useful comments. They also thank Rohan Churm, Gergely Hamvas, Florence Hubert, Vas Madouros, Dimitrios Papanastasiou, Iain de Weymarn, Tomasz Wieladek, and seminar participants at the Bank of England, 11th BMRCDEMS Conference and 47th Money, Macro and Finance Research Group Annual Conference for suggestions and comments. The views expressed in the paper are those of the authors and do not necessarily reflect the views of the Bank of England. Any remaining errors are the sole responsibility of the authors. Author e-mails: jeremy.chiu@bankofengland.co.uk and john.hill@bankofengland.co.uk. 


\section{Introduction}

The global financial crisis highlighted fragilities in wholesale funding markets and at intermediaries in those markets on which banks depended for wholesale funding. In September 2007 Northern Rock fell victim to the first run on a bank in the United Kingdom since 1878 when it lost access to the wholesale markets on which it relied for funding (see Shin 2009). Elevated funding costs have remained a key issue for bankers and policymakers in recent years, as highlighted by a recent Bank of England publication, Beau et al. (2014). At least partly in response to funding pressures, a number of banks in the United Kingdom have reviewed their business models and activities, leading to significant changes to their balance sheets and funding structures: banks have reduced their reliance on wholesale funding by financing more of their assets with deposits. The introduction of new liquidity standards under Basel III - the liquidity coverage ratio (LCR) and net stable funding ratio (NSFR) - also incentivize banks to grow their share of retail deposits (retail funding) at the expense of wholesale funding 1

As a result of these changes, it has become increasingly important for policymakers to be able to assess the stability of deposit bases against a range of shocks, both to individual banks and in aggregate, as banks transition towards their new steady-state funding structures. While a large body of existing literature highlights risks posed by wholesale funding, e.g., Acharya, Gale, and Yorulmazer (2011), we seek to draw attention to risks that retail funding may pose to individual banks and to the banking system as a whole.

This paper contributes to the literature by quantitatively studying the behavior of household deposit funding at major U.K. banks using an empirical macroeconomic methodology. We exploit a unique data set, compiled by the Bank of England, covering deposit rates and deposit balances for U.K. banks. The data are monthly and cover the period from January 2004 to December 2013. Together with other time-series data, we estimate a panel of linear Bayesian

\footnotetext{
${ }^{1}$ By way of illustration, under the LCR just 5 percent of stable retail deposits are assumed to run during the first thirty days following a stress. In contrast, the rate at which unsecured wholesale funding runs is assumed to be in the range of 75-100 percent.
} 
vector autoregression (BVAR) regression models employing "hierarchical priors" as described in Jarociński (2010). These priors allow us to pool short sample data during estimation while preserving dynamic heterogeneity across banks.

To identify structural shocks in the household deposits market, we adopt an agnostic approach along the lines of Faust (1998), Canova and de Nicolo (2002), and Uhlig (2005). We identify shocks by imposing a set of unique microfounded contemporaneous sign restrictions when estimating the panel of BVARs. These restrictions are provided by a stylized, one-period, linear, partial equilibrium model. The model characterizes the behavior of a representative household that supplies (retail) deposits to the banking system, and optimally allocates them across individual banks. The model also captures individual banks' optimal demand for retail deposits. This paper simultaneously studies four types of structural shock: (i) idiosyncratic retail deposit demand shock; (ii) aggregate retail deposit demand shock; (iii) idiosyncratic retail deposit supply shock; and (iv) aggregate retail deposit supply shock. The first two shocks work via the banking sector, whereas the latter two come from the household sector.

The empirical model is estimated over the full sample (January 2004-December 2013). To account for possible structural changes in banks' behavior following the onset of the global financial crisis, we also conduct split-sample analysis. We identify June 2007 as a structural break in retail deposit markets (shortly before the crisis at Northern Rock). Mindful that the pre-crisis sample (January 2004-June 2007) may be too short for estimation, we estimate the post-crisis sample (July 2007-December 2013) and proceed to report and compare these results against data from the full sample. Based on the impulse responses, we construct a measure called the "required average increase in deposit rate" (RAIDR). This is a dynamic measure designed to quantify by how much banks would have had to bid up their deposit rate in order to raise some fixed quantity of deposits in response to a shock. To adjust for differences in the pre-crisis and post-crisis periods, we also introduce a measure of the elasticity of household deposits with respect to the deposit rate to facilitate time-consistent comparisons.

Post-crisis sample estimates across banks and shocks suggest that in order to raise $£ 1$ billion of retail deposits, banks face a median 
RAIDR in the order of 5 basis points (bps) at the twelve-month horizon, 10 bps at the six-month horizon, and 20 bps at the threemonth horizon: As expected, the RAIDR is generally decreasing in the length of the time horizon. This implies that when banks are able to cover their deposit gap with less urgency, they are able to raise their deposit rates by less than when they are forced to cover the gap over a shorter horizon.

In terms of elasticities, we find that household retail deposits in the United Kingdom are rate inelastic. Post-crisis sample estimates show that elasticities lie in the range of 0.1 to 0.5 at the twelve-month horizon. Moreover, our results show that elasticities conditional on deposit demand shocks are larger than those conditional on deposit supply shocks, suggesting that banks find it more difficult to use deposit rates to mitigate deposit supply shocks.

By comparing the differences in the impulse responses and the computed metrics in the full and post-crisis samples, our estimates indirectly show that retail deposit behavior differs before and after the financial crisis. For example, the rate elasticity of retail deposits appears to have increased slightly following the financial crisis.

Collectively, our findings suggest that a retail-deposit funded bank may find it difficult (and costly) to attract deposit inflows quickly, but is increasingly able to mitigate shocks when it can raise retail deposits over longer horizons. It is unsurprising that banks are unable to raise deposits quickly at acceptable costs. Retail banks typically distinguish between so-called core and non-core deposits. Regulators and banks treat these core deposits as "sticky" and rate insensitive - customers rarely move these balances, which are held for primarily transactional reasons. This includes salary receipts, bill payments, and other household expenses. So the inflows and outflows from these deposit balances tend to approximately net out over time. The bulk of retail deposits are of this "core" type. So, from an aggregate perspective, it is not surprising that deposits are rate insensitive and tend to circulate between institutions slowly.

An implication of this result is that retail-funded banks may need alternative means of managing shocks (such as adequate liquidity coverage) in place to ensure they can ride out cyclical shocks in the short run. Moreover, our results suggest that policymakers and regulators should give further consideration to the impact of deposit 
supply shocks, as we find that banks are more vulnerable to this type of shock.

Our paper contributes to a growing body of empirical literature that seeks to study bank funding behavior. Damar, Meh, and Terajima $(2013,2015)$ study how wholesale funding can lead to bank procyclicality and the relevant implications to the real economy. Craig and Dinger (2013) relate deposit market competition to wholesale market conditions and examine their joint effect of the risk of bank assets. de Haan, van den End and Vermeulen (2015) use a panel BVAR to study the response of European banks' lending (volumes and rates) to wholesale funding shocks, identified by Cholesky decomposition. Our paper differs from theirs in that we focus on retail funding, and model retail deposit supply and demand shocks, and that our BVAR analysis omits lending data, due to data constraints and to ensure tractability. Perhaps closest to our paper is de Graeve and Karas (2014): using Russian deposit market data, they identify "bank-run shocks" by imposing both sign and heterogeneity restrictions. Our paper takes a step further by identifying a full set of deposit demand and supply shocks using sign restrictions.

This paper is also related to a large empirical literature studying retail banking activities. De Bondt (2002) provides evidence on retail bank interest rate pass-through using a vector error-correction model (VECM) framework. McQuinn and Woods (2012) model Irish financial institutions' corporate deposits using an error-correction model to infer long-run and short-run dynamics. Rughoo and Saranti (2014) investigate how the European Union retail banking sector is integrated by studying deposit and lending rates to the household sector before and after the global financial crisis. Acharya and Mora (2015) provide evidence that, based on the U.S. data, the traditional view of the provision of liquidity insurance by banks was possible only because of explicit support from the U.S. government.

There is also a significant body of theoretical work which seeks to model retail deposit markets and infer the behavior of household deposits. Diamond and Dybvig (1983) provides a classic reference on bank runs. Salop (1979) models bank competition spatially: "services" provided by each branch are a function of the spatial distance from where the household is located. Klemperer (1987) explains how switching costs affect the competitiveness of markets, the theory of which is applied to the market for bank deposits by Sharpe (1997). 
Bruche and Suarez (2010) present a theoretical model that captures how deposit insurance can create asymmetry between "savings-rich" and "savings-poor" regions which can lead to a freeze in the money market. While the literature tends to focus on identifying either deposit demand or supply shocks, this paper constructs a theoretical model to simultaneously identify structural demand and supply shocks in the deposits market.

The rest of the paper is structured as follows. Section 2 provides a brief overview of the modeling approach. Section 3 describes the theoretical model that we use to select the sign restrictions. Section 4 introduces the data set and provides a discussion of the panel of BVARs as a hierarchical model. Sections 5-7 present results and discussion of policy implications, followed by robustness checks. Section 8 concludes the paper with some discussion of future work.

\section{Overview of Modeling Approach}

This short section provides a high-level overview of the two-stage modeling approach that consists of an empirical model and a theoretical model. We also discuss some of the modeling choices we make. Subsequent sections describe the models in more detail.

\subsection{The Empirical Model}

The first stage of modeling involves the estimation of a linear panel of BVARs. With the employment of hierarchical priors, this model is particularly well suited to studying a group of heterogeneous units (banks), and allows us to pool information across banks to make efficient use of scarce data 2 The lack of comparable data on banks' wholesale funding activities and reliable, high-frequency data on banks' liquid asset holdings constrains our empirical modeling choices.

\footnotetext{
${ }^{2}$ The VECM is a common tool to study the co-movement of deposit rates, as in de Bondt (2002). The selection of this model hinges on long-run relationships between variables. There are two reasons we do not use VECM modeling: (i) our focus is not on modeling joint interest behavior; (ii) we find little theoretical backing for our choice variables displaying a long-run co-integrating relationship either.
} 
It is well known that the panel regression residuals are of reduced form and are likely to be a mixture of economically interpretable shocks. In order to identify the four structural shocks of interest, we follow the macroeconomic literature by imposing sign restrictions on the contemporaneous impulse responses, i.e., how variables endogenously respond on impact when structural shocks hit. These sign restrictions are based on a microfounded theoretical model which is discussed in the next subsection. We provide answers to policyrelevant questions based on this impulse response analysis.

\subsection{The Theoretical Model}

The second stage of modeling involves the construction of a theoretical model for structural shock identification. It is motivated by the need to decompose the reduced-form BVAR residuals into the four economically interpretable structural shocks, namely (i) idiosyncratic retail deposit demand shock; (ii) aggregate retail deposit demand shock; (iii) idiosyncratic retail deposit supply shock; and (iv) aggregate retail deposit supply shock. As mentioned, we take the sign-restrictions approach backed by a theoretical model 3 While the current macroeconomic dynamic stochastic general equilibrium (DSGE) model literature has developed sophisticated models on wholesale banking (Gertler and Kiyotaki 2015, Gertler, Kiyotaki, and Prestipino 2015), we have not yet seen a DSGE model simultaneously identifying structural demand and supply shocks in the deposits market. So we construct a tractable and stylized theoretical model for our own purposes.

We construct a one-period, linear, partial equilibrium model, featuring a representative household (supplier of deposits) and heterogeneous banks (demanders of deposits). Both the household and heterogenous banks make optimal decisions on the supply and the demand of retail deposits. The household "supplies" deposits based on a portfolio optimization problem; banks "demand" deposits

\footnotetext{
${ }^{3}$ Another popular way to identify structural shocks is the use of Cholesky decomposition, which makes ad hoc assumptions on whether certain variables respond to shocks contemporaneously. Under this identification scheme, the ordering of variables matters. Since this identification does not enable us to derive the deposit demand and supply shocks of interest, we do not take this approach.
} 
to meet funding needs, partly resulting from shocks in non-retail funding markets.

In light of data constraints and to ensure tractability, we make some modeling assumptions. In particular, we abstract from the maturity structure of banks' liabilities and other complexities of banks' funding dynamics - such as their ability to liquidate assets. We do not consider any theoretical implications of spillover effects from one bank to another either 4

In the following sections we describe the theoretical model and the microfounded sign restrictions on the shock-identification scheme. We proceed to provide details on the panel of BVARs and our estimation process.

\section{The Theoretical Model}

The theoretical model introduced in this section is used to provide a set of microfounded sign restrictions that uniquely identify the demand and supply shocks of interest in the household retail deposit market 5

\subsection{The Household's Optimization Problem}

The representative household is risk averse and takes all interest rates as given. It is endowed with some initial wealth, which is divided between cash (governed by an exogenous "liquidity preference" parameter) and non-cash assets. It then optimally allocates its non-cash wealth to some combination of a risky asset (e.g., equities) and a risk-free asset - funds deposited at banks. This stylized setup provides a framework in which to study how households rebalance their non-cash wealth portfolio between risky assets and risk-free deposits.

\footnotetext{
${ }^{4}$ Some readers may argue that a more complex model would capture additional non-linear features of deposit behavior which will make the model realistic. We contend that our one-period theoretical model, rather than giving a comprehensive explanation of banks' and households' behavior, provides a tractable way to identify endogenous variable responses on impact, as shown in table 1 . Since non-linear features likely set in after the first period of the shock, a more realistic but complicated theoretical model would likely result in a very similar contemporaneous identification scheme.

${ }^{5}$ From now on, household deposits are referred to simply as "deposits."
} 


\subsubsection{Supply of Aggregate Deposits}

The household seeks to maximize the risk-adjusted return of its portfolio, given an initial allocation of non-cash wealth. Deposits are treated as the risk-free asset in our setup - reflecting an implicit assumption that all household deposits are covered by deposit insurance 6

Given an initial allocation of wealth $w$, the household allocates a proportion $\varphi$ to cash and $1-\varphi$ to non-cash assets, where $\varphi$ is an exogenous parameter governing the household's liquidity preference. An exogenous increase in $\varphi$ causes a household to prefer to hold more cash - perhaps due to a loss of confidence in the banking system. Denote non-cash wealth as $w^{n c}=(1-\varphi) w$.

A simple portfolio choice problem is modeled. Given an allocation of non-cash wealth, the household invests in a portfolio comprising a risky asset and risk-free bank deposits. We denote $s_{r}$ as the share of wealth invested in risky assets, and $s_{f}$ as the share of wealth invested in risk-free deposits. By definition, $s_{r}+s_{f}=1$. Denote $R_{r} \sim d\left(\mu_{r}, \sigma_{r}\right)$ as the random return of the risky asset, and $\bar{r}$ as the aggregate return for the risk-free deposits defined in the next subsection $\sqrt{7}$ The end-of-period expected portfolio return $R_{p}$ can be written as

$$
R_{p}=\bar{r} s_{f}+R_{r} s_{r}
$$

We find $s_{r}$ by exploiting the fact that the variance of the risk-free return is zero. Based on (1), the variance of end-of-period wealth is

$$
\sigma_{p}^{2}=\sigma_{r}^{2} s_{r}^{2}
$$

implying

$$
s_{r}=\frac{\sigma_{p}}{\sigma_{r}} .
$$

${ }^{6}$ U.K. deposits made by private individuals to authorized firms have been protected by the Financial Services Compensation Scheme up to a limit of $£ 85,000$ from December 31, 2010, and the majority of U.K. household deposits are covered by this scheme.

${ }^{7}$ We assume that banks do not default and that the household knows $\bar{r}$ for certain. 
Given non-cash wealth and the standard deviation of returns on the risky asset, the household chooses to invest a larger share of its wealth in the risky asset if it chooses to have a higher variance in the return on its portfolio. The share of wealth to be invested in the risk-free asset is then

$$
s_{f}=1-s_{r}=1-\frac{\sigma_{p}}{\sigma_{r}} .
$$

Denote $D$ as the aggregate deposits supplied by the household. By definition, $D=s_{f} w^{n c}=s_{f}(1-\varphi) w$, and hence

$$
D=\left(1-\frac{\sigma_{p}}{\sigma_{r}}\right)(1-\varphi) w
$$

which specifies the aggregate supply of deposit: 8 to the banking system from the household sector 9

Proposition 1. Equation (4) implies $\frac{\partial D}{\partial \sigma_{p}}<0, \frac{\partial D}{\partial \varphi}<0$.

Proof. Results immediately follow from (4).

We interpret adverse aggregate deposit supply shocks (Agg-DS shocks) as either (i) the household's preference, given a liquidity preference $\varphi$, to hold a riskier investment portfolio (an increase in $\sigma_{p}$ ), probably during times of benign macroeconomic conditions; or (ii) an exogenous increase in $\varphi$, resulting in the household preferring to hold more of its wealth as cash-perhaps following a drop in confidence in the banking system during times of financial instability.

${ }^{8}$ Equilibrium condition (4) gives us a condition that the aggregate supply of deposits $D$ does not depend on the prevailing aggregate retail deposit rate $\bar{r}$ but on risk and liquidity preference parameters. This simplified condition helps us uniquely identify aggregate and idiosyncratic deposit supply shocks in the model. We stress that, as explained in the next subsection, the household's allocation of aggregate deposits across individual banks does indeed depend on each bank's deposit rate.

${ }^{9}$ Substituting (2) and (3) into (1) yields the opportunity set for one risky and risk-free asset: $R_{p}=\bar{r}+\sigma_{p} \frac{R_{r}-\bar{r}}{\sigma_{r}}$. In the $\left(R_{p}, \sigma_{p}\right)$ space, the slope of the line is described by $\frac{R_{r}-\bar{r}}{\sigma_{r}}$, also known as the Sharpe ratio. 


\subsubsection{Supply of Deposits to Individual Banks}

We assume that there is a continuum of banks $i \in[0,1]$ which are monopolistic competitors and hence have a degree of monopoly power. Denote $\eta>1$ as the elasticity of substitution across banks. The aggregate supply of deposits $D$ is treated as a composite good, and is defined by the constant elasticity of substitution (CES) aggregator 10

$$
D=\left(\int_{0}^{1} D_{i}^{1-\frac{1}{\eta}} d i\right)^{\frac{1}{1-\frac{1}{\eta}}}
$$

Denote $r_{i}$ as the deposit rate offered by bank $i$, which the household takes as given. Also denote $\psi_{i} \geq 1$ as an exogenous parameter dictating how much the household likes/dislikes bank $i$ 's deposit "service." We may think about it as the cost to the consumer of traveling to the bank, or the quality of the bank's customer service. Since we assume that the household treats (insured) deposits as risk free, we do not endogenously link this parameter to the health of the individual bank's balance sheet.

Instead, this parameter serves to differentiate between banks by capturing non-price factors. The closer this value is to one, the more the household "likes" that particular bank. The adjusted return a household receives from depositing with bank $i$ is $\frac{r_{i}}{\psi_{i}}$. A household depositing $\frac{D_{i}}{\left(r_{i} / \psi_{i}\right)}$ will receive $D_{i}$ at the end of the period. We interpret an increase in $\psi_{i}$ as an adverse idiosyncratic deposit supply shock (Id-DS shock) 11

The household minimizes its "expenditure" on deposits subject to supplying a given level of aggregate deposits. It solves

$$
\min _{D_{i}} \int_{0}^{1}\left(\frac{\psi_{i}}{r_{i}} D_{i}\right) d i
$$

subject to (5).

\footnotetext{
${ }^{10}$ Drechsler, Savov, and Schnabl (2014) takes a similar approach in modeling deposits for households.

${ }^{11}$ This shock is slightly more general than the "bank-run shock" in de Graeve and Karas (2014), who identify bank-run shocks as adverse deposit supply shocks that hit uninsured banks harder than insured ones in the Russian deposit market.
} 
Denote $\frac{1}{\bar{r}}$ as the Lagrange multiplier (or the shadow value) to the aggregate deposit constraint, where $\bar{r}$ is interpreted as the aggregate deposit rate. The Lagrangian reads

$$
L=\int_{0}^{1}\left(\frac{\psi_{i}}{r_{i}} D_{i}\right) d i-\frac{1}{\bar{r}}\left[\left(\int_{0}^{1} D_{i}^{1-\frac{1}{\eta}} d i\right)^{\frac{1}{1-\frac{1}{\eta}}}-D\right] .
$$

The first-order condition with respect to $D_{i}$ gives

$$
D_{i}=\left(\frac{r_{i} / \psi_{i}}{\bar{r}}\right)^{\eta} D
$$

The household's optimal supply of deposits to bank $i$ is increasing in the adjusted interest rate relative to the aggregate deposit rate.

In equilibrium, the household will allocate its deposits across banks $i$ and $j$ according to the relative adjusted deposit rates:

$$
\frac{D_{i}}{D_{j}}=\left(\frac{r_{i} / \psi_{i}}{r_{j} / \psi_{j}}\right)^{\eta}
$$

Substituting (6) into (5) gives the formula for the aggregate deposit rate $\bar{r}$ :

$$
\bar{r}=\left(\int_{0}^{1}\left(\frac{r_{i}}{\psi_{i}}\right)^{\eta-1} d i\right)^{\frac{1}{\eta-1}}
$$

Proposition 2. The aggregate supply of deposits from households is independent of the idiosyncratic deposit supply shock, i.e., $\frac{\partial D}{\partial \psi_{i}}=0$.

Proof. See appendix 1.

\subsection{Banks' Optimization Problem}

Recall that the banking system comprises a continuum of banks $i \in[0,1]$. Banks' "demand" for deposits for retail funding needs is motivated by an optimization problem between retail and non-retail funding (e.g., wholesale funding market). 
We make simplifying assumptions about the structure of banks' balance sheets. On the asset side, banks are assumed to hold a constant loan portfolio, $L_{i}$. Banks are not able to run down (liquid) assets in order to cover liquidity shocks; nor can they raise shortterm secured funding by pledging collateral to the central bank. On the liabilities side, we assume that banks face a simple portfolio choice between household deposit funding, $D_{i}$, and "other" funding, $F_{i}$. We abstract from modeling the maturity structure by assuming that all funding lasts for one period. Since this is a one-period model, banks face a static balance sheet and all household deposits can be raised in one period. All banks take the central bank's policy rate as given.

In combination, these assumptions mean that a bank can only respond to shocks by substituting between deposit funding and nondeposit/other funding. It does not permit a bank to increase its market share by, for example, building new branches, or improving its online/mobile banking service. Hence we assume away banks' ability to influence the parameter $\psi_{i}$.

\subsubsection{Demand for Deposits}

Each bank has monopoly power in setting the deposit rate $r_{i}\left(D_{i}\right)$ as it faces an upward sloping supply curve $D_{i}$ (see (6)). The "production" of deposits incurs a cost $C_{i}\left(D_{i}\right)$. The bank's marginal cost, $C_{i}^{\prime}\left(D_{i}\right)$, is assumed to be increasing in $D_{i}$ (i.e., $C_{i}^{\prime \prime}\left(D_{i}\right)>0$ ).

For the purpose of illustration, we can think of "other" funding as interbank borrowing. But the intuition developed in this section could be applied more generally to sources of funds that banks can use instead of retail deposits. The interest rate a bank $i$ has to pay for interbank loans can be decomposed into two components: a global interbank rate $\widetilde{r}$ and a bank-specific spread $s_{i}$. Assume that the spread $s_{i}=s_{i}\left(z, \sigma_{i}^{b}\right)$, where $s_{i}^{\prime}\left(\sigma_{i}^{b}\right)>0$ and $s_{i}^{\prime}(z)=\phi>0$ across all banks. The parameter $\sigma_{i}^{b}$ is interpreted as the idiosyncratic riskiness of interbank lending to bank $i$, whereas $z$ is interpreted as the riskiness of the U.K. interbank system as a whole. By definition, this assumption implies that a change in $z$ will cause the same change in spreads $s_{i}$ for all banks $i$.

A change in $\sigma_{i}^{b}$ corresponds to an idiosyncratic deposit demand shock (Id-DD shock). Specifically, a rise in the value of $\sigma_{i}^{b}$ is 
interpreted as an increase in the riskiness of lending to bank $i$ in "other" markets (e.g., interbank markets), prompting that particular bank to rebalance its liabilities portfolio away from "other" funding towards deposit funding. Moreover, this shock will also increase the bank spread $s_{i}$ for bank $i$ only. In contrast, an aggregate deposit demand shock (Agg-DD shock) is characterized by an increase in the common component $z$, which drives up bank spreads $s_{i}$ for all banks symmetrically, prompting all banks to demand additional deposits.

Defining the average spread across banks $s=\int_{0}^{1} s_{i}\left(z, \sigma_{i}^{b}\right) d i$ and an individual bank's spread relative to the market average spread $\widetilde{s}_{i}=s_{i}-s$, we arrive at the following proposition:

PROPOSITION 3. It follows that $\frac{\partial \widetilde{s}_{i}}{\partial z}=0$ and $\frac{\partial \widetilde{s}_{i}}{\partial \sigma_{i}^{b}}>0$ for a particular bank $i$.

Proof. See appendix 1.

This proposition states that the relative interbank spread for an individual bank goes up when it faces a bank-specific wholesale funding shock (a rise in $\sigma_{i}^{b}$ ), whereas the relative spread remains unchanged when the wholesale funding shock affects the banking system as a whole (a rise in $z$ ).

Bank $i$ attempts to minimize its funding cost function, which includes the total cost of retail funding, wholesale funding, and the cost of producing deposits, subject to the balance sheet constraint:

$$
\min _{D_{i}, F_{i}} \nabla=r_{i}\left(D_{i}\right) D_{i}+\left(\widetilde{r}+s_{i}\left(z, \sigma_{i}^{b}\right)\right) F_{i}+C_{i}\left(D_{i}\right)
$$

subject to

$$
L_{i}=D_{i}+F_{i}
$$

The first-order condition reads

$$
\frac{\partial r_{i}\left(D_{i}\right)}{\partial D_{i}} D_{i}+r_{i}\left(D_{i}\right)+C_{i}^{\prime}\left(D_{i}\right)=\widetilde{r}+s_{i}\left(z, \sigma_{i}^{b}\right)
$$

which implicitly defines the downward-sloping demand for deposits of each bank $i$. 


\subsection{Retail Deposits Equilibrium and Comparative Statics}

Equilibrium deposit rate $r_{i}^{*}$ and deposit balance $D_{i}^{*}$ for bank $i$ can be found by solving (6) and (10), taking $\bar{r}$ and $D$ as given. We derive comparative statics with respect to the parameters of interest in the model.

Proposition 4. Based on the deposit equilibrium conditions for bank $i$, we derive the following comparative statics for its equilibrium level of deposits $D_{i}^{*}$ :

$$
\frac{\partial D_{i}^{*}}{\partial \sigma_{i}^{b}}>0, \frac{\partial D_{i}^{*}}{\partial z}>0, \frac{\partial D_{i}^{*}}{\partial \psi_{i}}<0, \frac{\partial D_{i}^{*}}{\partial \sigma_{p}}<0, \frac{\partial D_{i}^{*}}{\partial \varphi}<0 .
$$

Proof. See appendix 1.

Proposition 5. Based on the deposit equilibrium conditions for bank $i$, we derive the following comparative statics for its equilibrium deposit rate $r_{i}^{*}$ :

$$
\frac{\partial r_{i}^{*}}{\partial \sigma_{i}^{b}}>0, \frac{\partial r_{i}^{*}}{\partial z}>0, \frac{\partial r_{i}^{*}}{\partial \psi_{i}}>0, \frac{\partial r_{i}^{*}}{\partial \sigma_{p}}>0, \frac{\partial r_{i}^{*}}{\partial \varphi}>0
$$

Proof. See appendix 1.

\subsection{Sign Restrictions for Shock Identification}

The theoretical model and accompanying comparative statics provide a set of microfounded restrictions to uniquely identify the contemporaneous effects brought about by the four types of structural shocks. Table 1 summarizes the shock-identification scheme, which can be described in words as follows:

- A deposit demand shock to an individual bank (Id-DD shock) is associated with an increase in the interbank spread of the bank relative to other banks in the system. The bank responds by bidding up for deposits, closing the funding gap by attracting additional deposits.

- A deposit demand shock to the banking system in aggregate (Agg-DD shock) is defined as a parallel shift in all banks' interbank spreads. Under this definition, relative spreads between 
Table 1. Identifying Restrictions

\begin{tabular}{l|c|c|c|c|}
\hline & $\begin{array}{c}\text { Id-DD Shock } \\
\left(\boldsymbol{\sigma}_{\boldsymbol{i}}^{\boldsymbol{b}} \uparrow\right)\end{array}$ & $\begin{array}{c}\text { Agg-DD Shock } \\
(\boldsymbol{z} \uparrow)\end{array}$ & $\begin{array}{c}\text { Id-DS Shock } \\
\left(\boldsymbol{\psi}_{\boldsymbol{i}} \uparrow\right)\end{array}$ & $\begin{array}{c}\text { Agg-DS Shock } \\
\left(\boldsymbol{\sigma}_{\boldsymbol{p}} \uparrow, \boldsymbol{\varphi} \uparrow\right)\end{array}$ \\
\hline $\boldsymbol{D}_{\boldsymbol{i}}$ & $>0$ & $>0$ & $<0$ & $<0$ \\
$\boldsymbol{r}_{\boldsymbol{i}}$ & $>0$ & $>0$ & $>0$ & $>0$ \\
$\boldsymbol{D}$ & $?$ & $?$ & $=0$ & $<0$ \\
$\widetilde{\boldsymbol{s}}_{\boldsymbol{i}}$ & $>$ & $=0$ & $?$ & $?$ \\
\hline \multicolumn{5}{|l}{ Notes: $D_{i}$ refers to a bank's stock of deposits, and $r_{\boldsymbol{i}}$ to its deposit rate. $D$ refers to } \\
aggregate household deposits, and $\widetilde{s}_{i}$ is bank $i$ 's "other" funding spread, relative to \\
the market average spread. '?' indicates no sign restriction.
\end{tabular}

banks are unchanged. All other effects are similar to an Id-DD shock.

- A deposit supply shock to an individual bank leads to an outflow of deposits (Id-DS shock) and causes it to increase its deposit rate. The aggregate deposit level is not affected: outflows are assumed to be redistributed across the banking system.

- A deposit supply shock to the banking system in aggregate (Agg-DS shock) is similar in nature to the individual deposit supply shock - the only difference being the negative impact on aggregate deposits. The decrease in aggregate deposits can be caused by either (i) households rebalancing their portfolios towards risky investments, typically in benign macroeconomic conditions; or (ii) households preferring to hold more cash, which could occur, for example, during a crisis of confidence in the banking system.

\section{The Empirical Model}

\subsection{Panels of VARs as a Hierarchical Linear Model}

Vector autoregression (VAR) models have been widely used in the empirical macro literature to model economic dynamics and identify structural shocks. As a researcher may also be interested in studying a group of heterogenous units (of the same underlying economic model), panel VARs which pool information across units 
have also been developed to make efficient use of scarce data for estimation.

Using $i=1, \ldots, I$ to represent each bank, $j=1, \ldots, p$ to represent the number of lags, and $t=1, \ldots, T$ to represent the time dimension of the data, we specify the panel-VAR model as follows:

$$
y_{i, t}=\sum_{j=1}^{p} A_{i, j} y_{i, t-j}+B_{i} X_{t}+C_{i} z_{i, t}+u_{i, t},
$$

where $y_{i, t}=\left[\begin{array}{llll}D_{i, t} ; & r_{i, t} ; & D_{t} ; & \widetilde{s}_{i, t}\end{array}\right]^{\prime}$ is a vector of four endogenous variables discussed in the theoretical model, $X_{t}$ is a vector of exogenous variables common across banks, $z_{i, t}$ represents the bank-specific constant terms (bank fixed effects), and $u_{i, t} \sim N\left(0, \Sigma_{i}\right)$ are reducedform shocks. In this setup, we assume away any static or dynamic interdependencies between banks, but we do preserve dynamic heterogeneity in the form of "partial pooling."

We propose the use of the hierarchical linear model of Gelman et al. (2003), following Jarociński (2010), for two reasons: the short data sample necessitates some form of pooling, and the assumption that bank coefficients shrink to some common mean is reasonable given the sample of banks under study. In this section, we provide the intuition of the hierarchical model and the corresponding priors imposed. For technical details, we refer the readers to appendix 2.

The first stage of hierarchy is to formalize the idea of "similarity." An exchangeable prior is imposed which specifies that banks' coefficients are assumed to be centred at a common mean with a hypervariance. In other words, such prior shrinks the bank coefficients to some common mean. The second stage of hierarchy involves a hyperprior about these prior parameters.

The hierarchical linear model allows us to specify the priors in the first stage of the hierarchy as non-informative and let the data inform the posterior common mean and hypervariance, given the assumed likelihood and prior structure. A greater degree of heterogeneity in the estimated bank coefficients implies that the posterior probability of a large hypervariance will be higher. Bank models which are more tightly estimated receive relatively more weight in the posterior common mean, compared with those in which the estimates are less precise. 
Specifically, we impose non-informative priors for banks' fixed effects $\left(z_{i, t}\right)$ and the common mean of the coefficients $A_{i, j}$ and $B_{i}$. Exchangeable priors (including a common mean and hypervariance) are imposed for the endogenous variables $\left(y_{i, t-j}\right)$ and common exogenous variables $\left(X_{t}\right)$. The hypervariance is scaled by a common parameter $\lambda$, which determines the overall tightness of the exchangeable prior. The econometrician imposes priors on $\lambda$, whose posterior distribution will be determined by the data and the priors. If the econometrician imposes strong priors such that the parameter $\lambda$ is equal to zero, the estimates will be equivalent to the full pooling of information across banks. In contrast, imposing $\lambda$ to center around relatively large values will result in each bank's model being farther from the common mean. As noted by Jarociński (2010), the estimation supposes that there is some intermediate range for $\lambda$, and the underlying data play a role in determining the posterior distribution of $\lambda$, which tends to be a very small number. We refer the readers to appendix 2 for a detailed description of our priors.

\subsection{Data and Estimation Details}

\subsubsection{Endogenous Variables}

The empirical estimation in this paper is based on a unique confidential data set compiled by the Bank of England. Effective deposit rates and deposit balances are collected from a sample of institutions that collectively account for at least 75 percent of sterling household deposits in the United Kingdom. Effective rates are calculated as a function of average loan/deposit balances and interest payable/receivable on those balances 12 The estimation makes use of total household deposit data (i.e., the stock of household deposits) and effective household deposit rates. Individual banks' stocks of deposits are converted into monthly percent changes and become the variable $D_{i}$. Four banks are used in our analysis.

To control for the impact of monetary policy on deposit rates, we express deposit rates as a spread over the risk-free rate in our

\footnotetext{
${ }^{12}$ For more information on effective rates, see http://www.bankofengland. co.uk/statistics/Pages/iadb/notesiadb/effective_int.aspx.
} 


\section{Table 2. Variables and Data for Estimation}

\begin{tabular}{|c|c|}
\hline Variable & Data Used for Estimation for Bank $i$ \\
\hline$D_{i}$ & $\begin{array}{l}\text { Monthly Percent Changes (Growth Rate) of Individual Bank } \\
\text { Deposit Data (\%) }\end{array}$ \\
\hline$r_{i}$ & $\begin{array}{l}\text { Effective Household Deposit Rate - Bank Rate (Deposit Spread, } \\
\quad \% \text { ) }\end{array}$ \\
\hline$D$ & Monthly Percent Changes of Household M4 (\%) \\
\hline$\widetilde{s}_{i}$ & $\begin{array}{l}\text { Individual Bank's Five-Year Euro Senior CDS Data - Average } \\
\text { Market Spread (Basis Points) }\end{array}$ \\
\hline
\end{tabular}

empirical implementation for $r_{i}$. Specifically, we define the deposit spread as the difference between the effective household deposit rate and the central bank policy rate (Bank rate) 13

We use monthly percentage changes to household M4 to proxy for aggregate deposits $D$. This setup allows for the interpretation of results in the most aggregate sense: responses to each bank are measured against the rest of the banking system, rather than just the other banks for which deposit balances are available. Similar (unreported) results are obtained if we simply sum balances across banks to proxy for aggregate deposits.

The spreads on other funding, $s_{i}$, are proxied by five-year eurodenominated senior credit default swaps (CDS) data. The average market spread is a simple average of CDS spreads across the banks. Table 2 summarizes the data and the variables used.

\subsubsection{Control Variables}

We also include a selection of variables, $X_{t}$, in the regression in order to control for exogenous macroeconomic conditions on the retail deposit market. We include the Bank of England's policy rate and the monthly growth rate of GDP (as estimated by the National Institute of Economic and Social Research). To proxy for international

\footnotetext{
${ }^{13}$ The model is partial equilibrium, and monetary policy is taken as given. This means that subtracting the central bank policy rate from the deposit rate results only in a change in the level. Neither the optimal conditions for deposit supply nor the comparative statics listed in proposition 5 are affected.
} 
wholesale funding conditions, we also include the Merrill Option Volatility Estimate index, which measures the implied interest rate volatility in the U.S. market.

\subsubsection{Estimation and Shock Identification}

We estimate the model using the full sample (January 2004December 2013) and the post-crisis sample (July 2007-December 2013). Table 3 reports the summary statistics for the data set. We resort to reporting averages in order to preserve the anonymity of banks.

We estimate the panel-VAR model (11) with six lags (i.e., $p=6) 14$ The model is estimated with Gibbs sampling, and each Gibbs simulation gives us estimates of the reduced-form innovations $u_{i, t}$ for each bank $i$. The shock-identification scheme (table 1) is imposed using Arias, Rubio-Ramirez, and Waggoner (2014) on these innovations to identify the four structural shocks of interest and to compute the impulse response functions 15 As robustness checks, we also consider pooled-estimation and bank-by-bank estimation and report the relevant results. Finally, convergence is monitored following Geweke (1992). Convergence details are reported in appendix 3 .

\footnotetext{
${ }^{14}$ There are two reasons for this choice. Firstly, as discussed in Han, Phillips, and Sul (2017), model selection criteria such as the Bayesian information criterion (BIC) are well known to be inconsistent in the presence of fixed effects in panel models. To that end, they propose modified criteria for panel autoregressions, but to our knowledge their criteria have not been generalized to panel vector autoregressions. Therefore we do not adopt BIC to identify the lag length in this paper. Secondly, the choice of this lag number reflects our consideration of properly capturing the model dynamics and the limited data sample. Ivanov and Kilian (2005) provides a survey on lag order selection and finds that most of the papers use at least six lags for monthly VAR models. Our choice of six lags is also consistent with Jarociński (2010), who performs estimation on monthly panel data sets.

${ }^{15}$ An interesting extension is to explicitly model monetary policy shocks. This will call for a more convoluted theoretical model in order to provide extra sign restrictions to identify such shocks, which have to be by construction orthogonal to our deposit supply and demand shocks. We leave this for future research.
} 


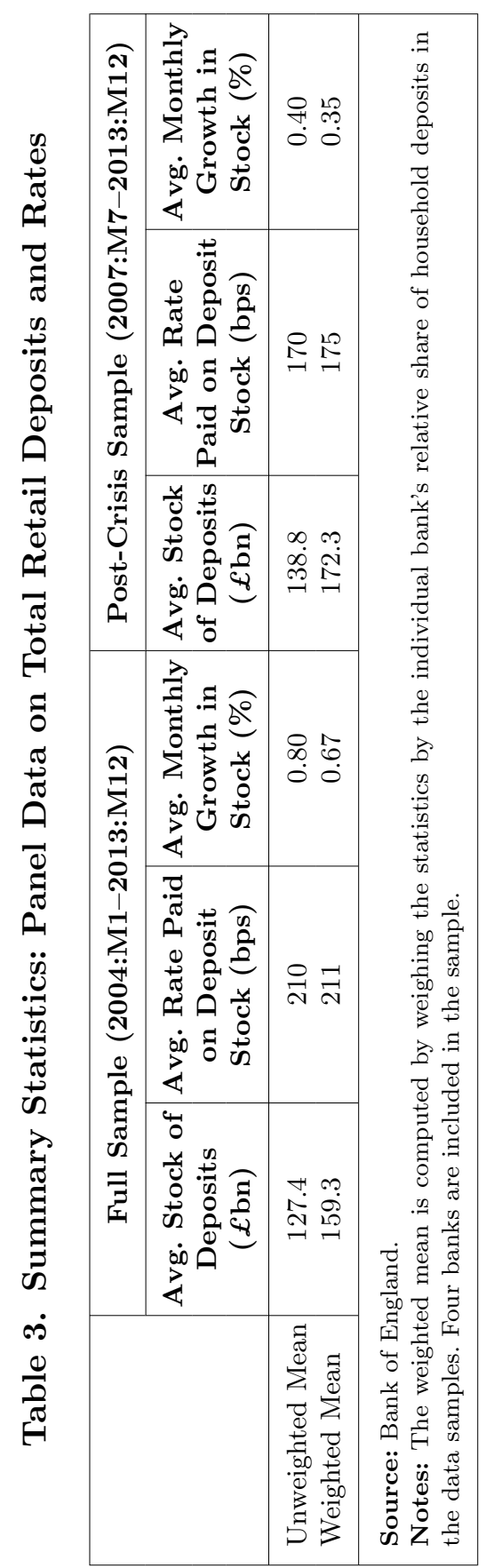




\section{Impulse Responses}

The model developed in this paper allows us to investigate banks' endogenous responses to cyclical shocks, because impulse responses (functions of the panel BVAR coefficients and our structural shock identification) summarize the dynamic transmission of structural shocks 16 Figure 1 illustrates a stylized deposit growth dynamic, where the level of deposit balances initially grows approximately loglinearly in steady state. Cyclical deposit demand or supply shocks create deposit gaps which a bank must close by raising additional deposits. Figure 2 shows a set of illustrative impulse responses fluctuating around the steady-state trend growth. Deposit demand and deposit supply shocks hit at $t_{0}$, both of which require the banks to raise their deposit rates to bid up for deposits. The growth rate of deposits deviates from trend temporarily, as a result of shocks and banks' mitigating actions, before returning to zero (i.e., no cyclical deviation) at time $t_{h}$. In this paper, we focus on studying the endogenous responses of retail deposit spreads and retail deposit growth rates 17

Figures 3 and 4 display the impulse responses of retail deposit spreads and deposit growth rates for an anonymous bank in the full and post-crisis data samples. Both variables are reported in the unit of percentage point (pp). The results are presented such that deposit growth is normalized on impact to an increase of 1 percentage point for deposit demand shocks (as in figure 3) and to a decrease of 1 percentage point for deposit supply shocks (as in figure 4). In other words, figure 3 displays a scenario of adverse wholesale funding shocks which, in equilibrium, cause banks to attract more retail deposits by raising retail deposit spreads, whereas figure 4 shows a scenario of adverse retail funding shocks which, in equilibrium, lead

\footnotetext{
${ }^{16}$ The system modeled is assumed to be at steady state, absent cyclical shocks and with deposit stocks growing at some "trend" rate. The emergence of cyclical shocks (impulses) perturbs the system, generating endogenous responses of modeled variables. Implicit in our modeling is the assumption that the cyclical shocks are small enough to be approximated by our linear empirical and theoretical models.

${ }^{17}$ Recall from section 3 that the model setup restricts banks' responses so that the interest rate paid on deposits is the only "lever" banks can pull to mitigate the impact of these structural shocks.
} 


\section{Figure 1. Stylized Dynamic for Household Deposits in Level}

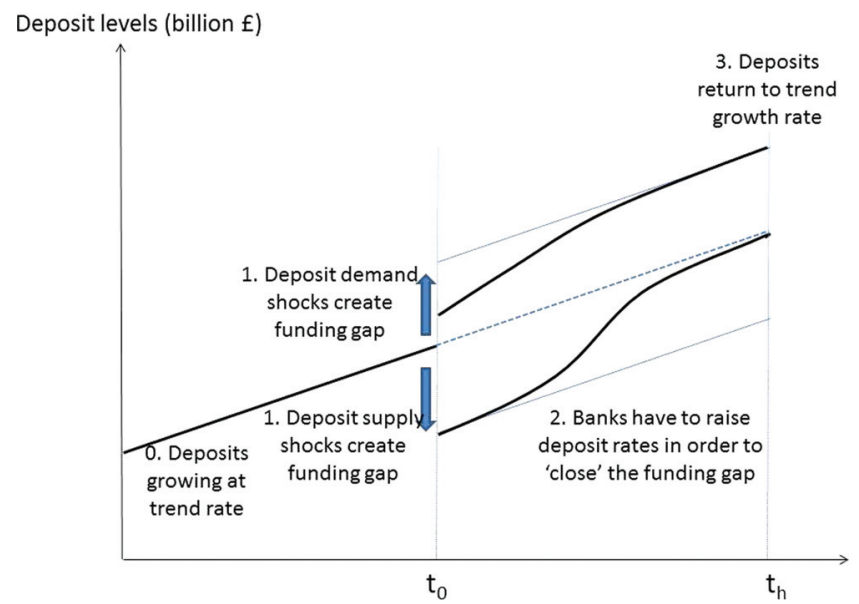

\section{Figure 2. Intuitive Impulse Responses of the Deposit Growth}

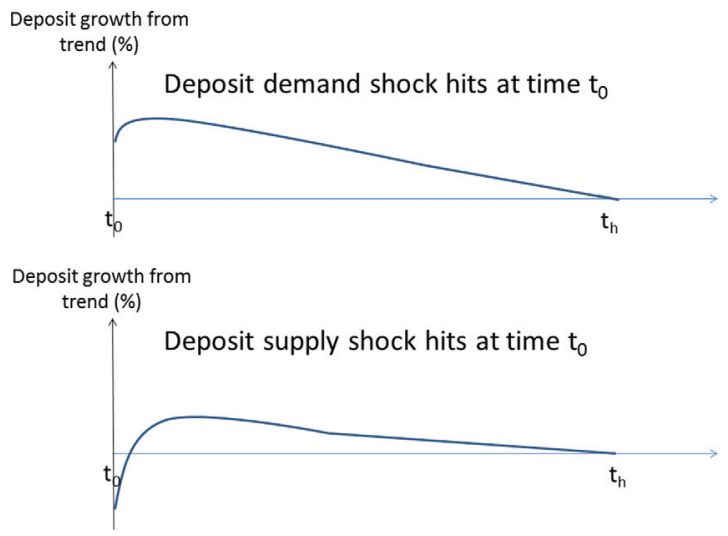

Note: This figure corresponds to a funding shortfall caused by deposit demand and supply shocks in figure 1 . 


\section{Figure 3. Impulse Responses of Deposit Growth Rates (left) and Retail Deposit Spreads (right) of an Anonymous Bank}
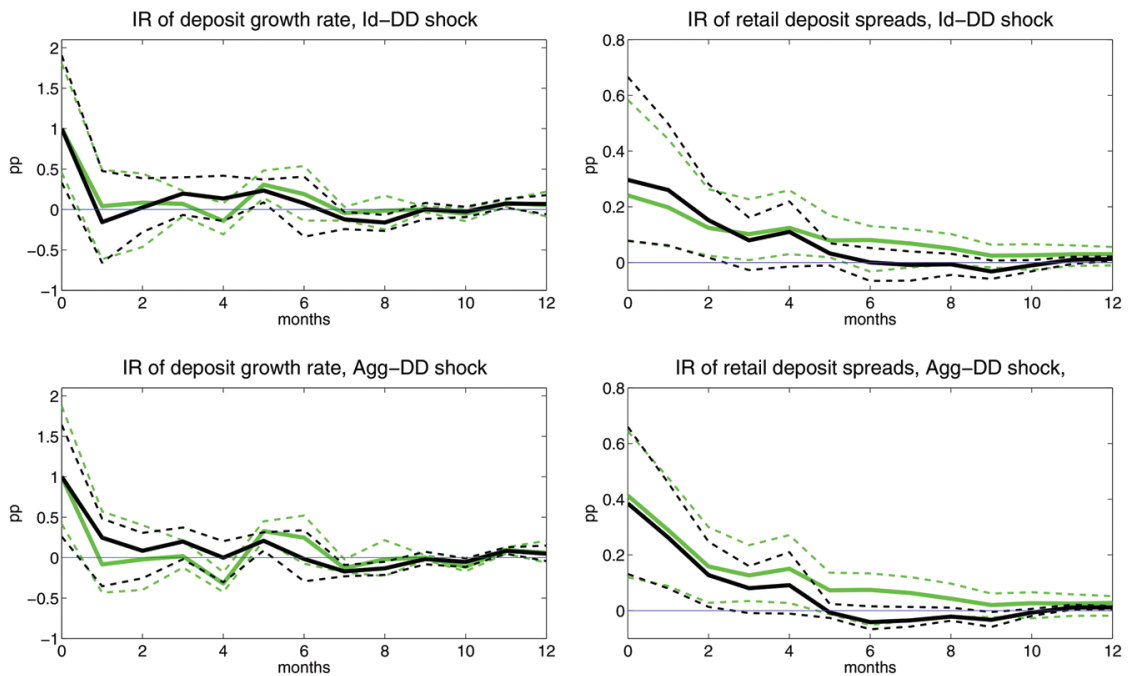

Notes: The responses are conditional on idiosyncratic deposit demand shocks (top panel) and aggregate deposit demand shocks (bottom panel). Black lines represent the results for the "post-crisis sample" data, whereas gray lines (green in online version) represent the results for the "full-sample" data. Solid lines correspond to the median impulse responses, and dotted lines to the 16th and 84th percentile of the responses.

banks to increase their retail deposit spreads. Gray lines (green in online version) denote the full-sample results 18 Black lines represent the post-crisis sample results 19

\subsection{Deposit Demand Shocks}

Figure 3 displays the impulse responses corresponding to idiosyncratic (top panel) and aggregate (bottom panel) deposit demand

\footnotetext{
${ }^{18}$ In the online version of this paper, available at http://www.ijcb.org, lines are shown in green and black for figures 3-9.

${ }^{19}$ The use of sign restrictions can only identify the size of shocks up to a proportional constant because of its set-identification properties, i.e., it admits a set of models satisfying the sign restrictions. We are not able to compare the size of structural shocks across banks.
} 


\section{Figure 4. Impulse Responses of Deposit Growth Rates (left) and Retail Deposit Spreads (right) of an Anonymous Bank}
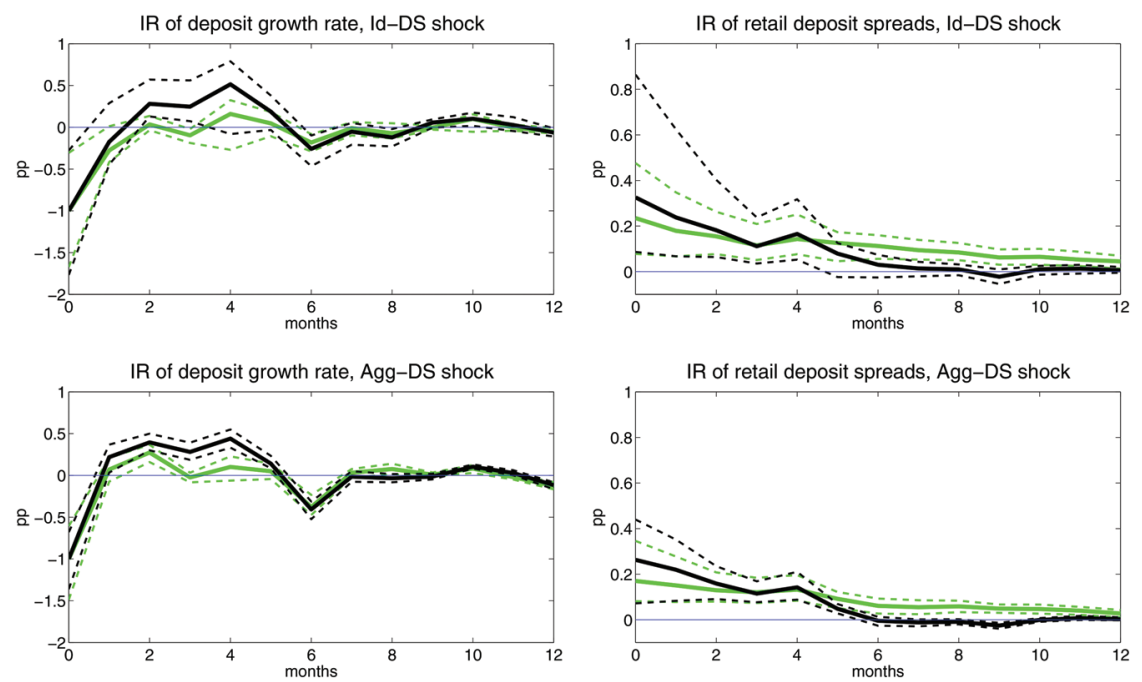

Notes: The responses are conditional on idiosyncratic deposit demand shocks (top panel) and aggregate deposit demand shocks (bottom panel). Black lines represent the results for the "post-crisis sample" data, whereas gray lines (green in online version) represent the results for the "full-sample" data. Solid lines correspond to the median impulse responses, and dotted lines to the 16th and 84th percentile of the responses.

shocks. The response of deposit growth rate appears to be similar across the two samples for both shocks. The increase in deposit growth rate is not very persistent: growth rates quickly revert to their steady-state value. This is particularly true in the full sample.

\subsection{Deposit Supply Shocks}

Figure 4 shows evidence that growth in retail deposits in the postcrisis sample (black lines) is higher in the first six months after supply shocks hit. This difference is especially stark for idiosyncratic deposit supply shocks (top-left panel), which show that this bank struggles to generate positive deposit growth in the full sample. It is also interesting to observe that this bank experiences a significant 
outflow of retail deposits six months after the supply shocks hit in both samples. Retail deposit spreads rise more on impact but quickly revert to trend after six months in the post-crisis sample.

\subsection{General Discussion}

Impulse responses across banks display heterogeneity in the level and degree of significance 20 Interestingly, the shapes of the responses are consistently different between data samples - as seen in figures 3 and 4 . This indirectly suggests that deposit behavior is structurally different before and after the financial crisis.

Two reasons potentially explain the differences across the samples: (i) The composition of banks' funding has changed as bank's business models have changed following the global financial crisis; and (ii) the degree of household risk aversion rose sharply during the crisis and has been slow to unwind. As a result, aggregate deposit supply is likely to be less constrained in the post-crisis period.

We transform these dynamic responses into two metrics in the following section to aid our interpretation of them.

\section{Two Computed Metrics Based on Impulse Responses}

The sensitivity of deposit balances to changes in deposit rates is relevant for the likely evolution of banks' funding costs, and hence the future profitability of banks. If the sensitivity varies significantly across different shocks, this would be useful information to provide to policymakers for the purpose of assessing the riskiness of deposit bases in different scenarios, as well as informing quantitative models of bank resilience (including stress tests). To address questions of this nature, we introduce two new metrics that capture the sensitivity of deposit balances to deposit rates: the required average increase in deposit rate and the dynamic deposit elasticity with respect to the deposit rate. Both metrics are based on impulse responses 21

\footnotetext{
${ }^{20}$ Impulse responses for the other three banks are shown in a separate chart appendix, which is available at the IJCB website, http://www.ijcb.org.

${ }^{21}$ It is important to note that both metrics are computed based on the cyclical increase in the stock of deposits; the trend growth of deposits is excluded from these calculations.
} 


\subsection{Required Average Increase in Deposit Rate}

When a bank raises its deposit rate to mitigate the effect of a cyclical shock, a key question to ask is by how much a bank has to bid up its average deposit rate to close the "funding" gap over a certain horizon. We call this the required average increase in deposit rate (RAIDR). Conditional on a structural shock and a horizon of $h$ months, RAIDR is computed by

$$
\begin{aligned}
& R A I D R_{h} \\
& =\frac{\text { Average change in deposit rates over } h \text { months }(\text { in bps) }}{\text { Cumulative change in deposits over } h \text { months }(£ b n)} .
\end{aligned}
$$

For visual comparison, we plot RAIDRs across the full range of the time horizon to form RAIDR curves. We consider the horizon $h$ to be three, six, nine, and twelve months 22

\subsection{Dynamic Deposit Elasticities}

As RAIDR results are potentially influenced by the steady-state levels of interest rates and deposit balances, they are less useful for comparisons across time periods. As shown in table 3, banks pay lower retail deposit rates in the post-crisis period, and the growth rate of deposit balances is also lower. To control for these interperiod differences, we propose a second metric: the $h$-month deposit rate elasticity, conditional on a structural shock for a particular bank:

$$
\eta_{h}=\frac{\text { Cumulative change in deposits over } h \text { months }(\text { in percent })}{\text { Average change in deposit rate over } h \text { months }(\text { in percent })} .
$$

The conditional elasticity measures, relative to the steady state, how responsive the growth in deposits (measured in percent) is with

\footnotetext{
${ }^{22}$ We also consider a slight variant of RAIDR curves normalized by 1 percent of the average size of the stock of deposits of the bank over each sample. This is to take into account the relative size of household deposit stocks (market share of deposits) held by each bank. Since the results are very similar, we report them in the separate chart appendix at http://www.ijcb.org.
} 


\section{Figure 5. RAIDR Curves per Billion Pound, Conditional on the Four Identified Structural Shocks}
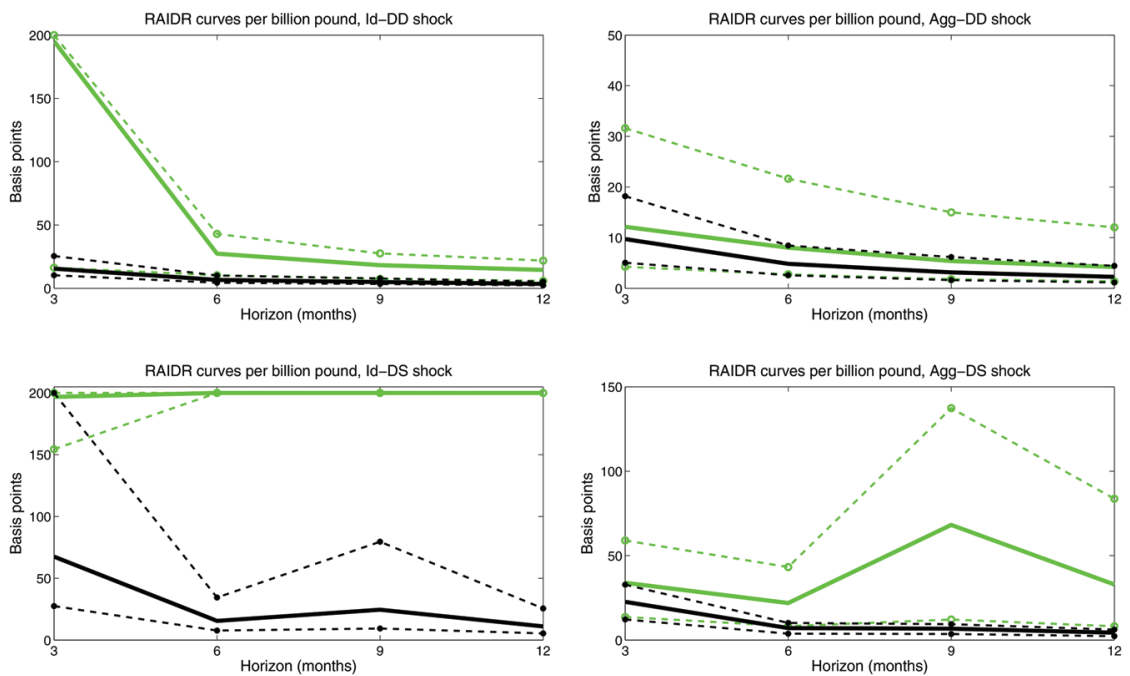

Notes: Gray lines (green in online version) denote the "full-sample" results, whereas black lines denote the "post-crisis" results. Computed by transforming the impulse responses to RAIDRs for each bank in the sample. Bold lines show the average RAIDR weighted by each bank's market share of household retail deposits, whereas dotted lines show the highest and lowest RAIDR values.

respect to the average change in retail deposit rate (measured in percent) over a given time horizon. For example, $\eta_{h}=1$ implies that when a shock hits now, an increase in the deposit rate of 1 percent from its steady-state level, maintained over $h$ months, leads to a 1 percent increase in the stock of deposits over and above the trend growth of deposits.

\subsection{Results and Discussion}

This section summarizes and discusses the results based on the two metrics outlined above. These are plotted in figures 5 and 6 . We report the highest and lowest values in the sample (denoted by dotted lines), and the average value weighted by individual bank's relative share of household deposits in the sample. Full-sample results are represented by gray lines (green in the online version); post-crisis 


\section{Figure 6. Household Dynamic Retail Deposits Elasticities Conditional on the Four Identified Structural Shocks}
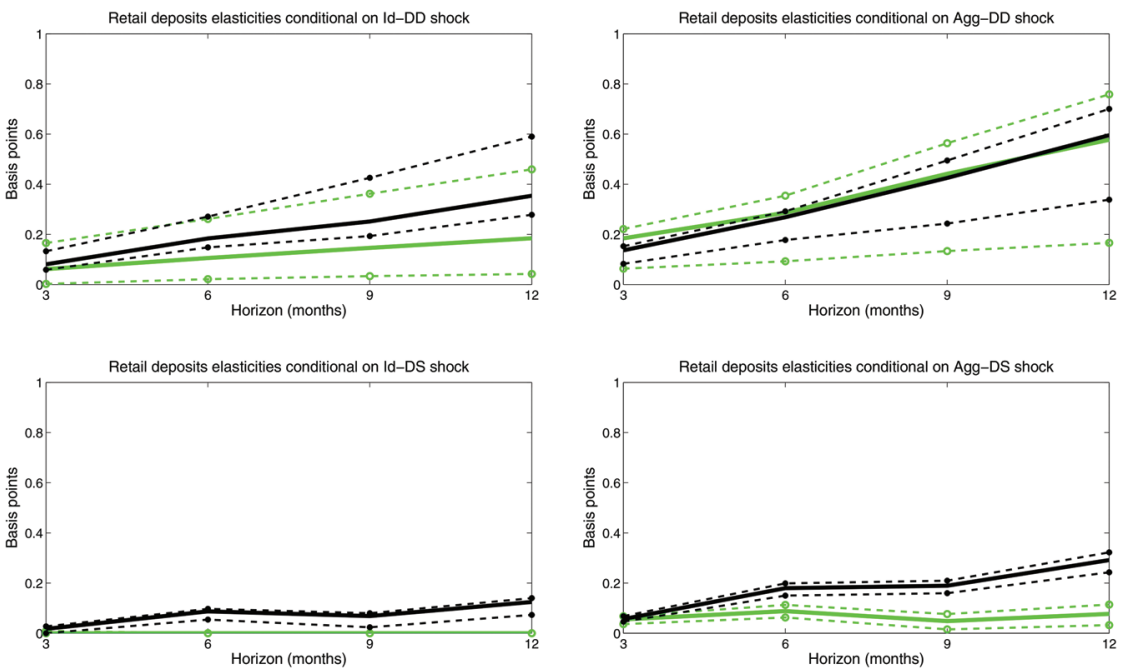

Notes: Gray lines (green in online version) denote the "full-sample" results, whereas black lines denote the "post-crisis" results. Bold lines show the average elasticity values weighted by each bank's market share of household retail deposits, whereas dotted lines show the highest and lowest elasticity values.

sample results are in black. By comparing these two sets of results, we make indirect inferences about deposit behavior in the United Kingdom before and after the financial crisis.

\subsubsection{Idiosyncratic and Aggregate Deposit Demand Shocks}

The top panel of figure 5 displays RAIDR curves for both types of demand shocks. These curves are downward sloping for all banks in both data samples. In the post-crisis period, RAIDRs start at a level of $15 \mathrm{bps}$ at $h=3$ and fall to around $3 \mathrm{bps}$ at $h=12$. RAIDRs are lower across the horizon post-crisis, implying that banks find it relatively easier to raise retail deposits in response to deposit demand shocks in this period.

We also observe a steep, downward-sloping RAIDR curve for idiosyncratic deposit demand shocks in the full-sample results (top-left panel). One sample bank's RAIDR is unusually high at $h=3$, taking 
a value in excess of 200 bps. We interpret this as banks being unable to mitigate the shock by using deposit rates to close the resulting deposit gap. Rather, these banks may have to resort to non-price mitigants, such as selling liquid assets, to cover these shocks.

In the post-crisis period, deposit responses are less different across banks, i.e., RAIDR curves are more closely clustered. This contrasts with the full-sample results, which show a much wider range of RAIDR values across all horizons, particularly for idiosyncratic deposit demand shocks.

The top panel of figure 6 shows the dynamic conditional deposit elasticities conditional on two types of demand shocks. Values are generally smaller than one, implying that bank deposits are rate inelastic. There has been an increase in elasticities for idiosyncratic demand shocks in the post-crisis sample, but elasticities for aggregate demand shocks are strikingly similar across both samples.

\subsubsection{Idiosyncratic Deposit Supply Shocks}

The lower-left panel of figure 5 shows that, when they face bankspecific deposit outflow shocks, banks have to persistently impose a higher deposit rate rise in the full-sample results but not in the postcrisis sample. We infer that there were challenges for banks to raise deposits in response to this type of shock before the crisis. This is consistent with our earlier comments on the impulse responses that show that banks struggle to generate positive deposit growth (top-left panel of figure 4).

Consistent with the RAIDR estimates, retail deposits conditional on this shock are found to be perfectly inelastic in the full sample (lower-left panel of figure 6). Deposit elasticities increase in the post-crisis sample but are still very rate inelastic, as the weighted elasticity is just 0.12 for the twelve-month horizon.

\subsubsection{Aggregate Deposit Supply Shocks}

As presented in the lower-right panel of figure 5, RAIDR curves are not decreasing in the length of the horizon in the full-sample results; in particular, there is a jump in the RAIDR at the nine-month horizon. In contrast, the RAIDR curves are strictly decreasing in the post-crisis sample results, and they are comparable to the RAIDR 
results with respect to deposit demand shocks. Conditional elasticities are also significantly larger in the post-crisis data (lower-right panel of figure 6).

However, we should point out one important caveat in the results: our model is likely to underestimate the difficulty banks face in retaining deposits in response to aggregate deposit supply shocks due to the absence of spillover effects. It is not possible for all banks to close a deposit gap simultaneously. Through changing their deposit rates to attract deposits, banks effectively "steal" deposits from elsewhere in the banking system, hence widening the deposit gap of other banks. This dynamic is likely to lead to other banks bidding up in response, making it difficult for banks to use deposit rates to attract net inflows of deposits.

\subsubsection{Policy Implications}

The above estimates provide useful information for policymakers. First, in order to raise $£ 1$ billion of retail deposits, banks face a median RAIDR in the order of 5 bps at the twelve-month horizon, 10 bps at the six-month horizon, and 20 bps at the three-month horizon, when we compare post-crisis sample RAIDR estimates across banks and shocks. In other words, the difference in RAIDR to close a deposit gap over a three-month horizon compared with a twelvemonth horizon is around a factor of 4 . This reflects the fact that deposits are typically difficult to raise quickly. This observation is further reinforced by the finding that deposits are rate inelastic. For the post-crisis sample, the twelve-month rate elasticity ranges from around 0.1 to 0.5 across banks and shocks and typically takes a value around 0.3 . This implies that a 1 percent increase in the deposit rate, maintained over twelve months, is associated with an increase in the stock of deposits, over and above the trend growth of deposits, of around 0.3 percent over the same horizon.

Second, to close a deposit gap equivalent to 1 percent of total deposits opened up by an idiosyncratic deposit demand shock, over a twelve-month horizon, a bank must increase the rate on the stock of deposits by around 5 bps post-crisis (the median of weighted RAIDRs post-crisis). To put that in perspective, a bank with a deposit base of $£ 50$ billion would incur an additional $£ 0.25$ billion per annum in interest expense. This provides one simple measure of 
the cost of a shock and may be useful for assessing banks' resilience to shocks 23

Third, evidence suggests that, although deposit rate elasticity has increased in the post-crisis period, rate elasticities with respect to deposit supply shocks are lower when compared with deposit demand shocks. Moreover, as discussed, our model may have underestimated the true RAIDR conditional on aggregate deposit supply shocks because of the absence of spillover effects.

\subsection{Robustness Checks}

We implement bank-by-bank and pooled-data estimation as robustness checks. We should note that pooling the data ignores bankspecific differences, whereas bank-by-bank estimation may produce biased estimates, as the data sample is relatively short. Nevertheless, there is some merit in comparing them against our baseline results. The corresponding RAIDR curves are reported in tables 4 and 5 .

We generally see downward-sloping RAIDR curves in the robustness checks exercises, especially for deposit demand shocks. It is still the case that deposits are less rate elastic conditional on deposit supply shocks. Bank-by-bank results show that elasticities range widely, which is not surprising when there is no pooling across the short data sample. Overall, we are reassured that the baseline results are reasonably robust.

\section{Historical Decomposition}

Historical decomposition is a useful technique for illustrating the historic paths of observed values of the endogenous variables in terms of the structural shocks and the path of the exogenous variables. This allows us to trace which of the structural shocks were driving movements in endogenous variables at different points in time. We can cross-check these descriptions with qualitative studies of key points in history as a means of validating the model's results.

In the interest of brevity, we only report results of the historical decomposition of two endogenous variables: retail deposit growth

\footnotetext{
${ }^{23}$ In practice, banks have a range of options, including non-price options, available to them when trying to mitigate these shocks.
} 
Vol. 14 No. 2 The Rate Elasticity of Retail Deposits in the UK

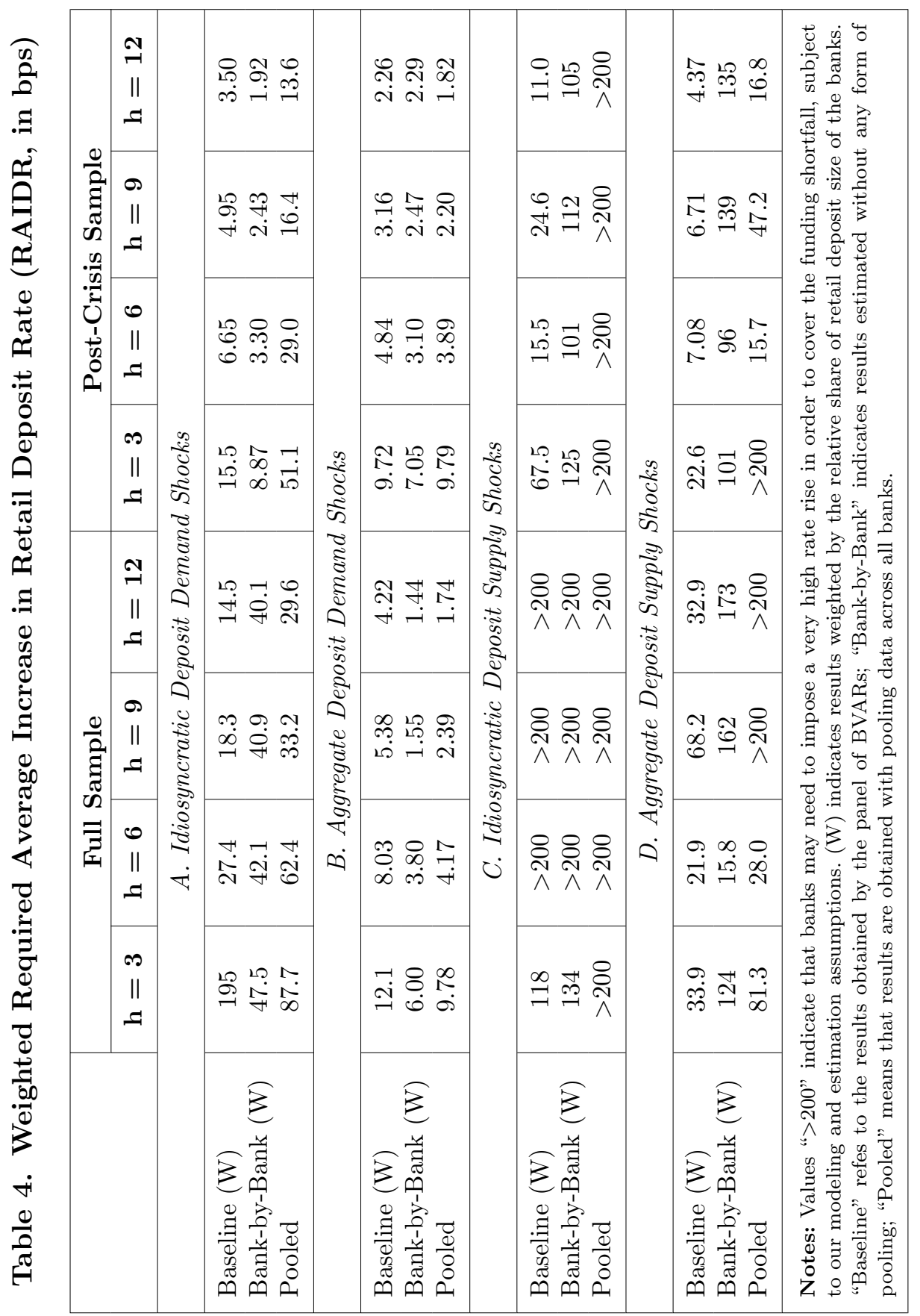




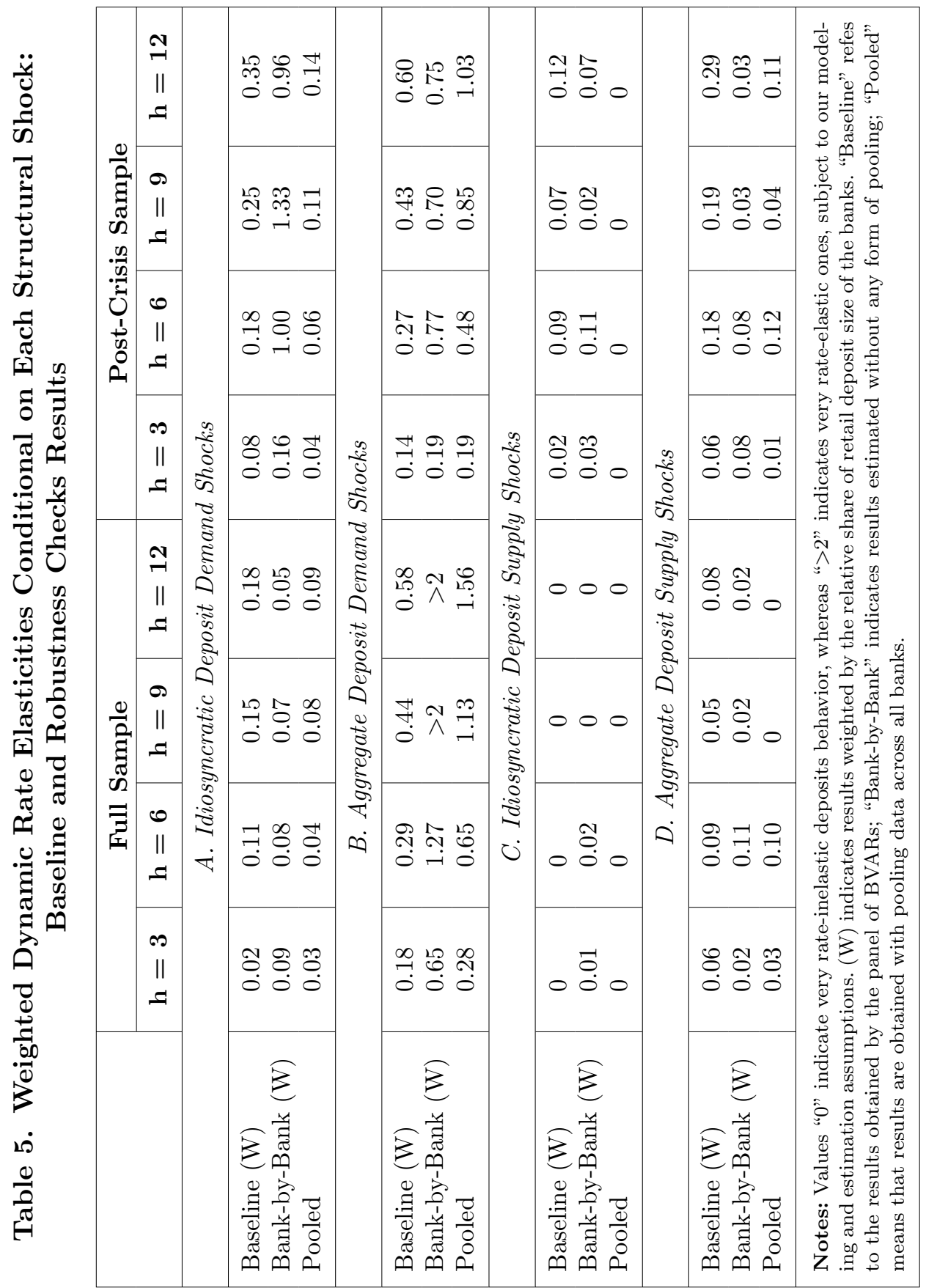




\section{Figure 7. Historical Decomposition for Retail Deposit Changes for an Anonymous Bank A in the Post-Crisis Sample}

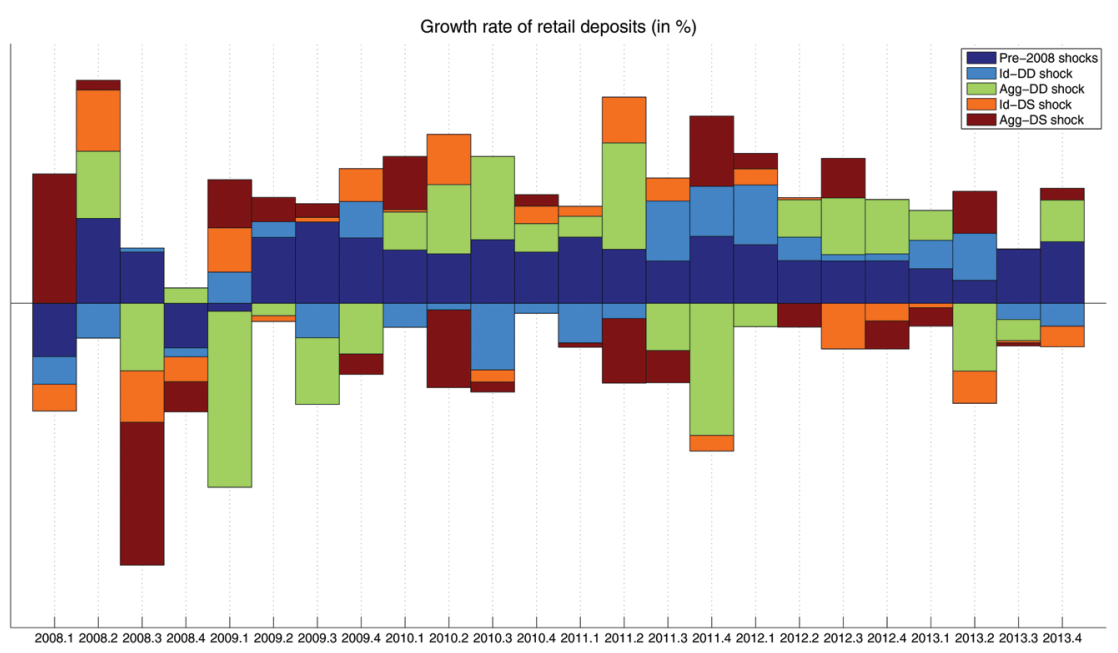

Notes: The actual data series and the y-axis labels are hidden to preserve confidentiality and anonymity. Variations not explained by the four structural shocks are denoted as "Pre-2008 Shocks."

rates and the relative CDS of some banks in the post-crisis sample. The contributions of the structural shocks to the observed data series are represented by shaded bars (online version is in color). By definition, the sum of the heights of the shaded (colored) bars equates to the value of the observed data. To preserve confidentiality and anonymity, neither the observed data series nor the y-axis labels are plotted.

\subsection{Retail Deposit Growth}

Figures 7 and 8 display the historical decomposition of retail deposit growth rates of two anonymous banks, which we call bank $\mathrm{A}$ and bank B. We observe the following:

- In 2008:Q3, aggregate deposit supply shocks largely explain the fall in deposit growth for both banks. The model apparently captures a deposit flight that affected banks (modeled 


\section{Figure 8. Historical Decomposition for Retail Deposit Changes for an Anonymous Bank A in the Post-Crisis Sample}

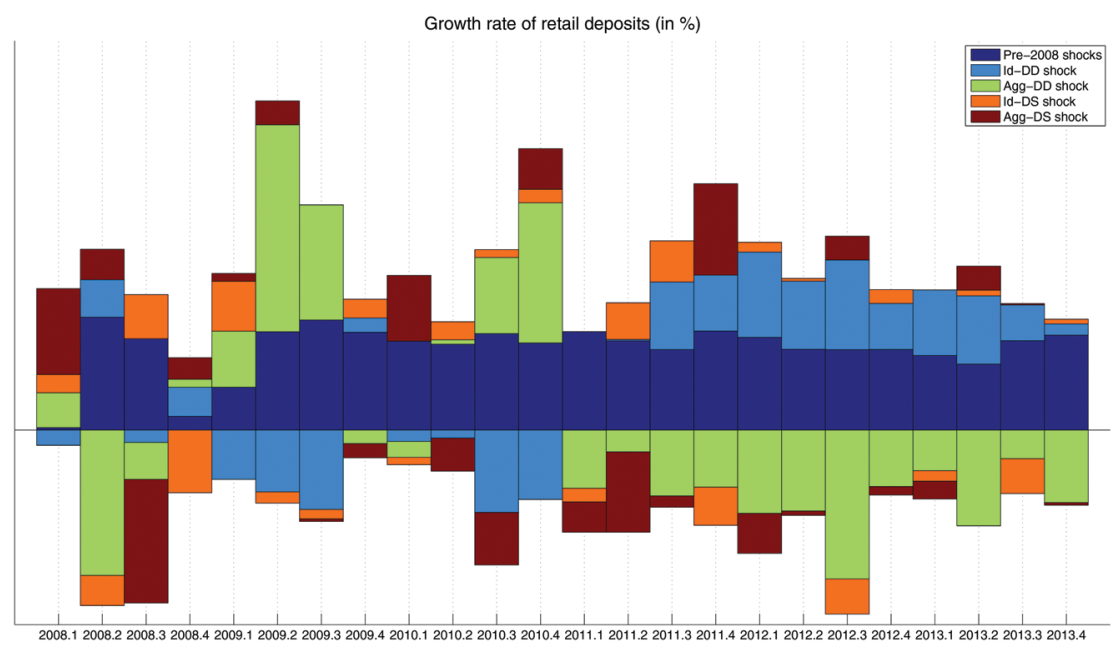

Notes: The actual data series and the y-axis labels are hidden to preserve confidentiality and anonymity. Variations not explained by the four structural shocks are denoted as "Pre-2008 Shocks."

by the model parameter $\varphi$ ), indicating that a flight to cash may have occurred at the onset of the global financial crisis.

- For bank A, aggregate deposit demand shocks play a key role in explaining the change in retail deposits between 2009 and 2013. For most of the quarters since 2010, the increase in deposit flow is explained by positive aggregate deposit demand shocks. This likely is explained by this bank substituting away from non-deposit funding (wholesale funding) sources.

- The increase in retail deposit flow experienced by bank B between 2009 and 2010, and especially the sharp increase in 2009:Q2-3 and 2010:Q4, is largely explained by aggregate deposit demand shocks. We take this as evidence that bank $\mathrm{B}$ was competing harder for deposits because it was finding it increasingly difficult to raise alternative sources of funding such as wholesale funding. Interestingly, this trend is reversed after 2011, in contrast to bank A. 


\section{Figure 9. Historical Decomposition for the Relative CDS Spreads for an Anonymous Bank X in the Post-Crisis Sample}

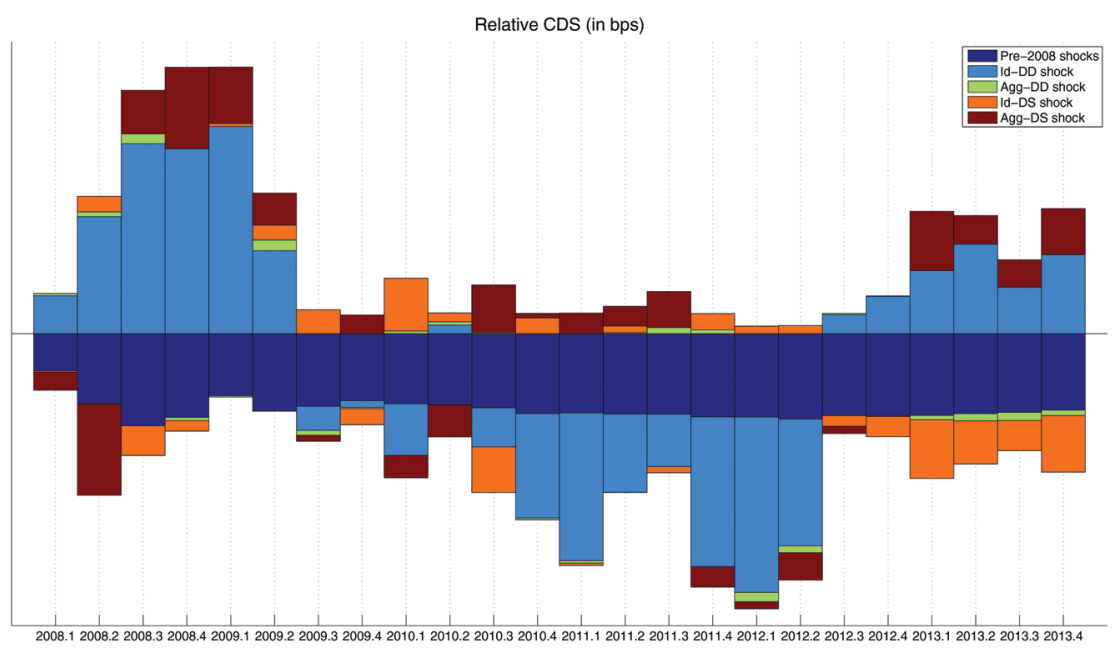

Notes: The actual data series and the y-axis labels are hidden to preserve confidentiality and anonymity. Variations not explained by the four structural shocks are denoted as "Pre-2008 Shocks."

\subsection{Relative $C D S$}

Figures 9 and 10 illustrate the historical decomposition for the relative CDS spreads of two anonymous banks, bank X and bank Y.

- Bank X's CDS spread rises relative to the other U.K. banks in 2008 and early 2009. This can be largely explained by positive idiosyncratic deposit demand shocks (caused by adverse idiosyncratic wholesale funding conditions) and, to some extent, aggregate deposit supply shocks. The main driving forces behind the fall in its CDS spread over the course of 2010 and 2012 are negative idiosyncratic deposit demand shocks, i.e., improving bank-specific wholesale funding conditions.

- In contrast, idiosyncratic deposit supply shocks play an important role in explaining the rise in the relative CDS spreads of bank Y, especially in the period of 2009 and 2012. Similarly, the subsequent decline in relative CDS spreads after 2012 is 


\section{Figure 10. Historical Decomposition for the Relative CDS Spreads for an Anonymous Bank Y in the Post-Crisis Sample}

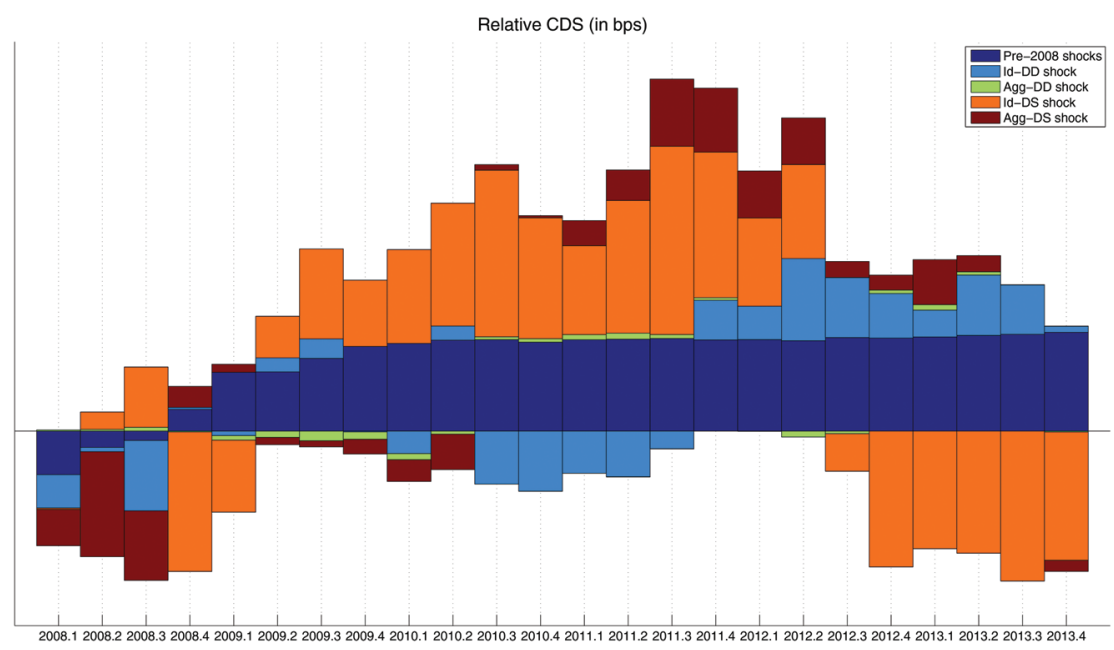

Notes: The actual data series and the y-axis labels are hidden to preserve confidentiality and anonymity. Variations not explained by the four structural shocks are denoted as "Pre-2008 Shocks."

largely attributable to this shock. This likely suggests that households lost confidence in this bank (relative to the other U.K. banks) following the financial crisis.

\section{Conclusion and Future Work}

We have presented a quantitative study on retail deposit behavior at major banks in the United Kingdom. We take advantage of a confidential data set of deposit rates and balances for four U.K. banks, which starts in January 2004. Having estimated a panel of BVARs with hierarchical priors, we uncover deposit demand and supply shocks, both to individual banks and in aggregate, from microfounded sign restrictions derived from a stylized partial equilibrium model. Based on the impulse response functions, we develop two metrics to estimate the cost for banks to close deposit gaps opened up following cyclical shocks. To account for the possible structural 
break in the deposit market behaviors during the financial crisis, we carry out split-sample analysis. We report and compare the results for the "full-sample" and "post-crisis" periods, highlighting the fact that differences may provide (indirect) empirical support for a possible structural change in household deposit behavior in the wake of the financial crisis.

We present some new and interesting empirical results. Our estimates show that when banks are able to cover their deposit gap with less urgency, they are able to raise their deposit rates by less than when they are forced to cover the gap over a shorter horizon. U.K. retail deposits are also shown to be rate inelastic. Our postcrisis sample estimates show that elasticities lie in the range of 0.1 to 0.5 at the twelve-month horizon. Moreover, our results show that elasticities conditional on deposits demand shocks are larger than those conditional on deposit supply shocks, suggesting that banks are more vulnerable to deposit supply shocks.

We recognize that there is scope for further work on this topic. In particular, our modeling framework could be enhanced in a number of ways. One area for future work is the introduction of non-linearities - including non-linear funding costs, spillover effects, or even bank defaults - to our theoretical and empirical models. Another avenue to explore is the relaxation of the restrictive assumptions made when modeling banks' balance sheets. For example, banks could be allowed to accumulate liquid assets which can be easily converted to cash when they face funding shortfalls. We leave these extensions to future research.

\section{Appendix 1. Proof of Propositions}

This section provides proofs for propositions $2-5$ in the main text.

Proof of Proposition 2

By chain rule, we rewrite

$$
\frac{\partial D}{\partial \psi_{i}}=\frac{\partial D}{\partial \bar{r}} \frac{\partial \bar{r}}{\partial \psi_{i}}=0
$$

Since the equilibrium aggregate deposit is not a function of $\bar{r}$ as shown in equation (4), implying that $\frac{\partial D}{\partial \bar{r}}=0$, results follow. 


\section{Proof of Proposition 3}

Note that $\frac{\partial \widetilde{s}_{i}}{\partial z}=\frac{\partial}{\partial z}\left(s_{i}-s\right)=\phi-\int_{0}^{1} \phi d i=0$. For a change in $\sigma_{i}^{b}$ of bank $i, s_{i}^{\prime}\left(\sigma_{i}^{b}\right)>0$ but $s_{j}^{\prime}\left(\sigma_{i}^{b}\right)=0, \forall j \neq i$. The market average spread $s$ will move less than one-for-one compared with the individual bank spread $s_{i}$. Therefore $\frac{\partial \widetilde{s}_{i}}{\partial \sigma_{i}^{b}}=\frac{\partial}{\partial \sigma_{i}^{b}}\left(s_{i}-s\right)=$ $s_{i}^{\prime}\left(\sigma_{i}^{b}\right)-\int_{0}^{1} s_{j}^{\prime}\left(\sigma_{j}^{b}\right) d j>0$.

\section{Proof of Proposition 4}

Considering the equilibrium deposit demand (10), and the equilibrium supply of aggregate deposit (4), as well as the following two equations derived from the equilibrium supply of deposits to an individual bank $i(6)$ :

$$
\begin{aligned}
r_{i}\left(D_{i}\right) & =\psi_{i} \bar{r}\left(\frac{D_{i}}{D}\right)^{\frac{1}{\eta}} \\
\frac{\partial r_{i}\left(D_{i}\right)}{\partial D_{i}} & =\frac{\psi_{i} \bar{r}}{\eta D}\left(\frac{D_{i}}{D}\right)^{\frac{1}{\eta}-1}
\end{aligned}
$$

we obtain the equilibrium condition

$$
\psi_{i} \bar{r}\left(1+\frac{1}{\eta}\right)\left[\frac{D_{i}}{(1-\varphi) w\left(1-\frac{\sigma_{p}}{\sigma_{r}}\right)}\right]^{\frac{1}{\eta}}+C_{i}^{\prime}\left(D_{i}\right)=\widetilde{r}+s_{i}\left(z, \sigma_{i}^{b}\right)
$$

This is a non-linear equation in $D_{i}$. Define $\Delta=1-\frac{\sigma_{p}}{\sigma_{r}}>0$, and recall our assumption that $C_{i}^{\prime \prime}\left(D_{i}\right)>0$ and $s_{i}^{\prime}\left(\sigma_{i}^{b}\right)>0$. By implicit function theorem, we derive the following derivatives:

$$
\begin{aligned}
& \frac{\partial D_{i}}{\partial \sigma_{i}^{b}}=\frac{s_{i}^{\prime}\left(\sigma_{i}^{b}\right)}{\psi_{i} \bar{r}\left(1+\frac{1}{\eta}\right) \frac{1}{\eta D}\left(\frac{D_{i}}{D}\right)^{\frac{1}{\eta}-1}+C_{i}^{\prime \prime}\left(D_{i}\right)}>0 \\
& \frac{\partial D_{i}}{\partial z}=\frac{1}{\psi_{i} \bar{r}\left(1+\frac{1}{\eta}\right) \frac{1}{\eta D}\left(\frac{D_{i}}{D}\right)^{\frac{1}{\eta}-1}+C_{i}^{\prime \prime}\left(D_{i}\right)}>0
\end{aligned}
$$


Vol. 14 No. 2 The Rate Elasticity of Retail Deposits in the UK

$$
\begin{aligned}
& \frac{\partial D_{i}}{\partial \psi_{i}}=\frac{-\bar{r}\left(1+\frac{1}{\eta}\right)\left(\frac{D_{i}}{\Delta}\right)^{\frac{1}{\eta}}}{\psi_{i} \bar{r}\left(1+\frac{1}{\eta}\right) \frac{1}{\eta D}\left(\frac{D_{i}}{D}\right)^{\frac{1}{\eta}-1}+C_{i}^{\prime \prime}\left(D_{i}\right)}<0 \\
& \frac{\partial D_{i}}{\partial \sigma_{p}}=\frac{\bar{r} \psi_{i}\left(1+\frac{1}{\eta}\right) \frac{1}{\eta} \frac{D_{i}}{w \Delta^{2}}\left(\frac{D_{i}}{\Delta}\right)^{\frac{1}{\eta}-1} \frac{1}{\sigma_{r}^{2}}}{\psi_{i} \bar{r}\left(1+\frac{1}{\eta}\right) \frac{1}{\eta D}\left(\frac{D_{i}}{D}\right)^{\frac{1}{\eta}-1}+C_{i}^{\prime \prime}\left(D_{i}\right)}<0 \\
& \frac{\partial D_{i}}{\partial \varphi}=\frac{\bar{r} \psi_{i}\left(1+\frac{1}{\eta}\right) \frac{1}{\eta} \frac{D_{i}}{w \Delta}\left(\frac{D_{i}}{\Delta}\right)^{\frac{1}{\eta}-1} \frac{1}{(1-\varphi)^{2}}}{\psi_{i} \bar{r}\left(1+\frac{1}{\eta}\right) \frac{1}{\eta D}\left(\frac{D_{i}}{D}\right)^{\frac{1}{\eta}-1}+C_{i}^{\prime \prime}\left(D_{i}\right)}<0 .
\end{aligned}
$$

\section{Proof of Proposition 5}

Similarly, by plugging (6) into (14), we can solve for the equilibrium deposit rate:

$$
\begin{gathered}
\psi_{i} \bar{r}\left(1+\frac{1}{\eta}\right)\left[\frac{D_{i}}{D}\right]^{\frac{1}{\eta}}+C_{i}^{\prime}\left(D_{i}\right)=\widetilde{r}+s_{i}\left(z, \sigma_{i}^{b}\right) \\
\left(1+\frac{1}{\eta}\right) r_{i}+C_{i}^{\prime}\left(\left(\frac{r_{i} / \psi_{i}}{\bar{r}}\right)^{\eta}(1-\varphi) w\left(1-\frac{\sigma_{p}}{\sigma_{r}}\right)\right)=\widetilde{r}+s_{i}\left(z, \sigma_{i}^{b}\right),
\end{gathered}
$$

which is also a non-linear equation in $r_{i}$. Again by implicit function theorem, we derive the relevant derivatives:

$$
\begin{gathered}
\frac{\partial r_{i}}{\partial \sigma_{i}^{b}}=\frac{s_{i}^{\prime}\left(\sigma_{i}^{b}\right)}{1+\frac{1}{\eta}+C_{i}^{\prime \prime}\left(D_{i}\right) \frac{\eta(1-\varphi) w}{\psi_{i} \bar{r}}\left(\frac{r_{i} / \psi_{i}}{\bar{r}}\right)^{\eta-1}\left(1-\frac{\sigma_{p}}{\sigma_{r}}\right)}>0 \\
\frac{\partial r_{i}}{\partial z}=\frac{1}{1+\frac{1}{\eta}+C_{i}^{\prime \prime}\left(D_{i}\right) \frac{\eta(1-\varphi) w}{\psi_{i} \bar{r}}\left(\frac{r_{i} / \psi_{i}}{\bar{r}}\right)^{\eta-1}\left(1-\frac{\sigma_{p}}{\sigma_{r}}\right)}>0 \\
\frac{\partial r_{i}}{\partial \psi_{i}}=\frac{s_{i}^{\prime}\left(\psi_{i}\right)+C_{i}^{\prime \prime}\left(D_{i}\right)(1-\varphi) w \eta\left(1-\frac{\sigma_{p}}{\sigma_{r}}\right) \frac{r_{i}}{\psi_{i}^{2} \bar{r}}\left(\frac{r_{i}}{\psi_{i} \bar{r}}\right)}{1+\frac{1}{\eta}+C_{i}^{\prime \prime}\left(D_{i}\right) \frac{\eta(1-\varphi) w}{\psi_{i} \bar{r}}\left(\frac{r_{i} / \psi_{i}}{\bar{r}}\right)^{\eta-1}\left(1-\frac{\sigma_{p}}{\sigma_{r}}\right)}>0
\end{gathered}
$$




$$
\begin{gathered}
\frac{\partial r_{i}}{\partial \sigma_{p}}=\frac{C_{i}^{\prime \prime}\left(D_{i}\right) \frac{(1-\varphi) w\left(1-\frac{\sigma_{p}}{\sigma_{r}}\right)}{\sigma_{r}^{2}}\left(\frac{r_{i} / \psi_{i}}{\bar{r}}\right)^{\eta}}{1+\frac{1}{\eta}+C_{i}^{\prime \prime}\left(D_{i}\right) \frac{\eta(1-\varphi) w}{\psi_{i} \bar{r}}\left(\frac{r_{i} / \psi_{i}}{\bar{r}}\right)^{\eta-1}\left(1-\frac{\sigma_{p}}{\sigma_{r}}\right)}>0 \\
\frac{\partial r_{i}}{\partial \varphi}=\frac{C_{i}^{\prime \prime}\left(D_{i}\right) \frac{w\left(1-\frac{\sigma_{p}}{\sigma_{r}}\right)}{\sigma_{r}^{2}}\left(\frac{r_{i} / \psi_{i}}{\bar{r}}\right)^{\eta}}{1+\frac{1}{\eta}+C_{i}^{\prime \prime}\left(D_{i}\right) \frac{\eta(1-\varphi) w}{\psi_{i}}\left(\frac{r_{i} / \psi_{i}}{\bar{r}}\right)^{\eta-1}\left(1-\frac{\sigma_{p}}{\sigma_{r}}\right)}>0 .
\end{gathered}
$$

\section{Appendix 2. Priors}

This section is drawn heavily from Jarociński (2010) and from Jarociński (2008), the corresponding unpublished appendix.

Further defining $x_{i t}=\left[y_{i, t-1}^{\prime}, \ldots, y_{i, t-p}^{\prime}, X_{t}\right]$, and stacking $y_{i, t}^{\prime}$, $x_{i, t}^{\prime}$, and $z_{i, t}^{\prime}$ for all $t$, we rewrite equation (11) as

$$
Y_{i}=X_{i} \widetilde{B}_{i}+Z_{i} \Gamma_{i}+U_{i}
$$

where $\widetilde{B}_{i}=\left[A_{i, 1}^{\prime}, \ldots, A_{i, p}^{\prime}, B_{i}^{\prime}\right]^{\prime}$. Let $\overrightarrow{y_{i}}=\operatorname{vec} Y_{i}, \beta_{i}=\operatorname{vec} \widetilde{B}_{i}$, $\gamma_{i}=\operatorname{vec} \Gamma_{i}$; the likelihood function for bank $i$ can then be written as

$$
p\left(\overrightarrow{y_{i}} \mid \beta_{i}, \gamma_{i}, \Sigma_{i}\right)=N\left(\left(I_{N} \otimes X_{i}\right) \beta_{i}+\left(I_{N} \otimes Z_{i}\right) \gamma_{i}, \Sigma_{i} \otimes I_{T_{i}}\right) .
$$

\section{First Stage of Hierarchy (Exchangeable Prior)}

This is a stage where we estimate the bank-specific coefficients by assuming that the dynamics of bank $i$ centers on some unknown common mean $\bar{\beta}$ and the hypervariance $\Lambda_{i}$ (which is called the "exchangeable prior"). Specifically, the conditional posterior distribution of $\beta_{i}$ is

$$
p\left(\beta_{i} \mid \bar{\beta}, \Lambda_{i}\right)=N\left(\bar{\beta}, \Lambda_{i}\right)
$$

We assume non-informative priors for $\bar{\beta}$ (the common mean) (we will discuss the priors for $\Lambda_{i}$ below). As for the estimation of $\gamma_{i}$ (the 
fixed effects) and $\Sigma_{i}$ (bank-specific variance), we respectively assume non-informative and standard diffuse prior:

$$
\begin{gathered}
p(\bar{\beta}) \propto 1 \\
p\left(\gamma_{i}\right) \propto 1 \\
p\left(\Sigma_{i}\right) \propto\left|\Sigma_{i}\right|^{-\frac{1}{2}(N+1)} .
\end{gathered}
$$

The motivation for non-informative priors is that we want to ensure that the estimation of $\bar{\beta}, \Sigma_{i}$, and $\gamma_{i}$ is entirely data driven. To conserve space, we do not report the conditional posterior distributions of these parameters but refer the readers to Jarociński (2008).

\section{Second Stage of Hierarchy (Hyperprior)}

The second stage involves hyperpriors which govern the common mean and the hypervariance $\Lambda_{i}$, which denotes the variance of $\beta_{i}$ around the common mean $\bar{\beta}$. Following Jarociński (2010), this variance matrix is tightly paramaterized in a way specified by the specification of the Minnesota prior, where the off-diagonal terms are set to zero. In the VAR of bank $i$, the coefficient of variable $k$ in equation $n$ has a variance equal to

$$
\operatorname{var}\left(\beta_{i}(k, n)\right)=\lambda \frac{\widehat{\sigma}_{i, n}^{2}}{\widehat{\sigma}_{i, k}^{2}} .
$$

Note that $\widehat{\sigma}_{i}$ is computed as the estimated standard error in the univariate L-th order autoregression of this variable. Two observations are in order. Firstly, all variances are scaled by the common parameter $\lambda$. Secondly, each coefficient's variance is scaled by a factor adjusting for the size of the coefficient. It can be immediately seen that $\lambda$ determines the overall tightness of the exchangeable prior, where $\lambda \rightarrow 0$ approaches full pooling and a relatively large $\lambda$ approach bank-by-bank estimation. We adopt the following form of inverted gamma density governing the prior for $\lambda$ :

$$
p(\lambda) \propto \lambda^{-\frac{v+s}{2}} \exp \left(-\frac{1}{2} \frac{s}{v}\right) .
$$


It can be shown that the hyperprior is uninformative when the values of $s$ and $v$ are set at zero. In our baseline estimation, our results are robust against a range of (loose) priors values imposed on $\lambda$, with the values of $s$ and $v$ set between the range of $1 \times 10^{-7}$ and $1 \times 10^{-9}$. The conditional posterior distribution of $\lambda$, as shown in Jarociński (2010), will be determined by the hyperprior and the data.

\section{Appendix 3. Convergence}

For estimation, 1,020,000 draws are executed, with the first 20,000 draws treated as burn-in. Every 1,000th draw is retained for impulse response analysis and inference. To monitor convergence, we follow the Z-score test described in Geweke (1992). We here focus on testing the $\lambda$ chain, whose square root (i.e., $\sqrt{\lambda}$ ) converges to a posterior median $2 \times 10^{-5}$ with a standard deviation of $5 \times 10^{-6}$.

The test involves checking whether the mean of the first 10 percent of the Markov chains and the mean of the last 50 percent of the sequence are equal. Formally, denoting $\widetilde{M}$ as the Markov chain, and $\widetilde{D}=\overline{\widetilde{M}}_{\text {last } 50 \%}-\overline{\widetilde{M}}_{\text {first } 10 \%}$, where $\overline{\widetilde{M}}$ denotes the mean of the chain, the Z-score is constructed as

$$
Z=\frac{\widetilde{D}-0}{S E(\widetilde{D})}
$$

The standard error $S E(\widetilde{D})$ is computed using the heteroskedasticity and autocorrelation consistent (HAC) estimator. In converged chains, Z-scores should have a standard normal distribution. The Z-score for $\lambda$ in our baseline estimation is smaller than 0.1 in both samples, indicating that convergence is achieved.

\section{References}

Acharya, V., D. Gale, and T. Yorulmazer. 2011. "Rollover Risk and Market Freezes." Journal of Finance 66 (4): 1177-1209. Acharya, V., and N. Mora. 2015. "A Crisis of Banks as Liquidity

Providers." Journal of Finance 70 (1): 1-43. 
Arias, J., J. Rubio-Ramirez, and D. Waggoner. 2014. "Inference Based on SVARs Identified with Sign and Zero Restrictions: Theory and Applications." International Finance Discussion Paper No. 1100, Board of Governors of the Federal Reserve System.

Beau, E., J. Hill, T. Hussain, and D. Nixon. 2014. "Bank Funding Costs: What Are They, What Determines Them and Why Do They Matter?" Quarterly Bulletin (Bank of England) 54 (4): 370-84.

Bruche, M., and J. Suarez. 2010. "Deposit Insurance and Money Market Freezes." Journal of Monetary Economics 57 (1): 45-61. Canova, F., and G. de Nicolo. 2002. "Monetary Disturbances Matter for Business Fluctuations in the G-7." Journal of Monetary Economics 49 (6): 1131-59.

Craig, B., and V. Dinger. 2013. "Deposit Market Competition, Wholesale Funding, and Bank Risk." Journal of Banking and Finance 37 (9): 3605-22.

Damar, H. E., C. Meh, and Y. Terajima. 2013. "Leverage, BalanceSheet Size and Wholesale Funding." Journal of Financial Intermediation 22 (4): 639-62.

. 2015. "Effects of Funding Portfolios on the Credit Supplies of Canadian Banks." Staff Working Paper No. 15-10, Bank of Canada.

de Bondt, G. 2002. "Retail Bank Interest Rate Pass-through: New Evidence at the Euro Area Level." Working Paper No. 136, European Central Bank.

de Graeve, F., and A. Karas. 2014. "Evaluating Theories of Bank Runs with Heterogeneity Restrictions." Journal of the European Economic Association 12 (4): 969-96.

de Haan, L., J. W. van den End, and P. Vermeulen. 2015. "Lenders on the Storm of Wholesale Funding Shocks: Saved by the Central Bank?" Working Paper No. 456, De Nederlandsche Bank.

Diamond, D., and P. Dybvig. 1983. "Bank Runs, Deposit Insurance, and Liquidity." Journal of Political Economy 91 (3): 401-19.

Drechsler, I., A. Savov, and P. Schnabl. 2014. "The Deposits Channel of Monetary Policy." Mimeo.

Faust, J. 1998. "The Robustness of Identified VAR Conclusions about Money." Carnegie-Rochester Series on Public Policy 49 (December): 207-44.

Gelman, A., J. Carlin, H. Stern, and D. Rubin. 2003. Bayesian Data Analysis. Second edition. London: Chapman \& Hall/CRC. 
Gertler, M., and N. Kiyotaki. 2015. "Banking, Liquidity, and Bank Runs in an Infinite Horizon Economy." American Economic Review 105 (7): 2011-43.

Gertler, M., N. Kiyotaki, and A. Prestipino. 2015. "Wholesale Banking and Bank Runs in Macroeconomic Modelling of Financial Crises." Mimeo.

Geweke, J. 1992. "Evaluating the Accuracy of Sampling-Based Approaches to Calculating Posterior Moments." In Bayesian Statistics 4, ed. J. M. Bernando, J. O. Berger, A. P. Dawid, and A. F. M. Smith. London: Oxford University Press.

Han, C., P. Phillips, and D. Sul. 2017. "Lag Length Selection in Panel Autoregression." Econometric Reviews 36 (1-3): 225-40.

Ivanov, V., and L. Kilian. 2005. "A Practitioner's Guide to Lag Order Selection for VAR Impulse Response Analysis." Studies in Nonlinear Dynamics and Econometrics 9 (1): Article 2.

Jarociński, M. 2008. "Additional Materials for the Paper: Responses to Monetary Policy Shocks in the East and the West of Europe: A Comparison." Unpublished appendix.

- 2010. "Responses to Monetary Policy Shocks in the East and the West of Europe: A Comparison." Journal of Applied Econometrics 25 (5): 833-68.

Klemperer, P. 1987. "Markets with Consumer Switching Costs." Quarterly Journal of Economics 102 (2): 375-94.

McQuinn, K., and M. Woods. 2012. "Modelling the Corporate Deposits of Irish Financial Institutions: 2009-2010." Research Technical Paper No. 2/RT/12, Central Bank of Ireland.

Rughoo, A., and N. Sarantis. 2014. "The Global Financial Crisis and Integration in European Retail Banking." Journal of Banking and Finance 40 (March): 28-41.

Salop, S. 1979. "Monopolistic Competition with Outside Goods." Bell Journal of Economics 10 (1): 141-56.

Sharpe, S. 1997. "The Effect of Consumer Switching Costs on Prices: A Theory and Its Applications to the Bank Deposit Market." Review of Industrial Organization 12 (1): 79-94.

Shin, H. 2009. "Reflections on Northern Rock: The Bank Run that Heralded the Global Financial Crisis." Journal of Economic Perspectives 23 (1): 101-19.

Uhlig, H. 2005. "What Are the Effects of Monetary Policy on Output? Results from an Agnostic Identification Procedure." Journal of Monetary Economics 52 (2): 381-419. 